\title{
An Sp185/333 gene cluster from the purple sea urchin and putative microsatellite-mediated gene diversification
}

\author{
Chase A Miller ${ }^{1,3 \dagger}$, Katherine M Buckley ${ }^{2,4 \dagger}$, Rebecca L Easley ${ }^{2,5}$, L Courtney Smith ${ }^{2 *}$
}

\begin{abstract}
Background: The immune system of the purple sea urchin, Strongylocentrotus purpuratus, is complex and sophisticated. An important component of sea urchin immunity is the Sp185/333 gene family, which is significantly upregulated in immunologically challenged animals. The Sp185/333 genes are less than $2 \mathrm{~kb}$ with two exons and are members of a large diverse family composed of greater than 40 genes. The S. purpuratus genome assembly, however, contains only six Sp185/333 genes. This underrepresentation could be due to the difficulties that large gene families present in shotgun assembly, where multiple similar genes can be collapsed into a single consensus gene.

Results: To understand the genomic organization of the Sp185/333 gene family, a BAC insert containing Sp185/333 genes was assembled, with careful attention to avoiding artifacts resulting from collapse or artificial duplication/ expansion of very similar genes. Twelve candidate BAC assemblies were generated with varying parameters and the optimal assembly was identified by PCR, restriction digests, and subclone sequencing. The validated assembly contained six Sp185/333 genes that were clustered in a $34 \mathrm{~kb}$ region at one end of the BAC with five of the six genes tightly clustered within $20 \mathrm{~kb}$. The Sp185/333 genes in this cluster were no more similar to each other than to previously sequenced Sp185/333 genes isolated from three different animals. This was unexpected given their proximity and putative effects of gene homogenization in closely linked, similar genes. All six genes displayed significant similarity including both $5^{\prime}$ and $3^{\prime}$ flanking regions, which were bounded by microsatellites. Three of the Sp185/333 genes and their flanking regions were tandemly duplicated such that each repeated segment consisted of a gene plus $0.7 \mathrm{~kb} 5^{\prime}$ and $2.4 \mathrm{~kb} \mathrm{3'}$ of the gene ( $4.5 \mathrm{~kb}$ total). Both edges of the segmental duplications were bounded by different microsatellites.

Conclusions: The high sequence similarity of the Sp185/333 genes and flanking regions, suggests that the microsatellites may promote genomic instability and are involved with gene duplication and/or gene conversion and the extraordinary sequence diversity of this family.
\end{abstract}

\section{Background}

Invertebrate immune systems are marked by an array of complex and sophisticated mechanisms for recognizing and responding to microbes [1-4]. A few systems that highlight this complexity are reshaping the paradigm that invertebrate immune systems were thought to be simple. The genes that encode fibrinogen-related

\footnotetext{
* Correspondence: csmith@gwu.edu

† Contributed equally

2Department of Biological Sciences, George Washington University,

Washington, DC, 20052, USA

Full list of author information is available at the end of the article
}

proteins (FRePs) in the freshwater snail Biomphalaria glabrata diversify through somatic diversification and point mutation of a small gene set [5]. Arthropod $D S C A M$ genes employ extensive alternative splicing to generate thousands of unique mRNAs [6-8] that encode proteins involved in phagocytosis by hemocytes [9] and may bind specifically to the infecting pathogen [10]. In higher plants, a variety of classes of $R$ genes exhibit disease resistance capabilities, and create and maintain diversity by sequence exchange and recombination (reviewed in [11]). Furthermore, a number of gene families function in immunity in which the mechanisms

\section{Biomed Central}


of diversification have not been investigated, such as the variable region-containing chitin-binding proteins (VCBPs) in protochordates [12-14].

The diverse, immune related gene family called 185/ 333, has been identified in several species of sea urchins [15-19]; D.A. Raftos, M. Roth, N.M. Dheilly, unpublished; K.M. Buckley, L.C. Smith, unpublished). The best understood of these homologues is the Sp185/333 gene family in the purple sea urchin, Strongylocentrotus purpuratus. Sp185/333 genes appear to have an immunological role and are highly expressed in coelomocytes responding to challenge with whole bacteria $[17,20]$ lipopolysaccharide $[17,18], \beta-1,3$-glucan, double-stranded RNA [18], and peptidoglycan [21]. Sea urchin larvae express Sp185/333 in blastocoelar cells when grown with marine microbes [16]. Consistent with an immune function, the Sp185/333 gene family is extraordinarily diverse. Alignment of the Sp185/333 sequences defines blocks of shared sequence known as elements based on the locations of large gaps (Figure 1) [17]. The variable presence and absence of these elements in different genes defines element patterns. Analysis of the evolutionary histories of these elements suggests that the extant genes are the result of recent diversification through frequent recombination such that the genes contain a mosaic distribution of element sequences and appear to be hybrids of other extant genes [22]. The gene family is estimated to contain around 50 genes based on three lines of evidence: 1) statistical analysis of the unique $S p 185 / 333$ genes given the total number cloned from three individual animals, 2) quantitative PCR (qPCR) analysis of alleles in sea urchin genomic DNA (gDNA), and 3) estimates from BAC library screens $[16,19,22]$. PCR amplification of intergenic regions suggests that at least some of the genes are closely linked and are positioned in various orientations [15]. The S. purpuratus genome assembly (v2.5), however, contains only six Sp185/333 genes on two scaffolds [23].

Shotgun sequence assembly is the standard method for quick and efficient assembly of BACs and whole genomes but there are problems in correctly assembling regions with repetitive elements. The most common type of gap in 'finished' genomes are unresolved heterochromatin regions, which are mainly composed of repetitive elements [24,25]. Much effort has gone into improving the assembly of these types of regions and some progress has been made with assembling transposons using specific transposon-based approaches [26]. However, these methods fail when applied to the assembly of other repetitive elements. A detailed study of misassembled segmental duplications in the 'finished' human genome shows that shotgun strategies consistently mis-assemble segmental duplications that are at least $15 \mathrm{~kb}$ and share at least 97\% identity [27]. Although shotgun assembly is extremely flexible and powerful, it can be modified to improve results especially when a specifically defined goal is included in the approach $[25,28,29]$. The significant underrepresentation of $S p 185 / 333$ genes in the sea urchin genome compared to our estimates of the gene family size may stem from two possible sources. First, the numbers of trace sequences with $S p 185 / 333$ sequence that were used to assemble the genome are fewer than expected, and may result from gene deletions from BAC inserts during growth of the cultures. This possibility will be tested in the future. Second, the genes may be incorrectly assembled in the genome because repetitive sequences are commonly mis-assembled and are often collapsed onto a single genomic location [24,25,27]. This second possibility is addressed below.

We report here the first follow-up to the problem of assembling the $S p 185 / 333$ genes, and show how the

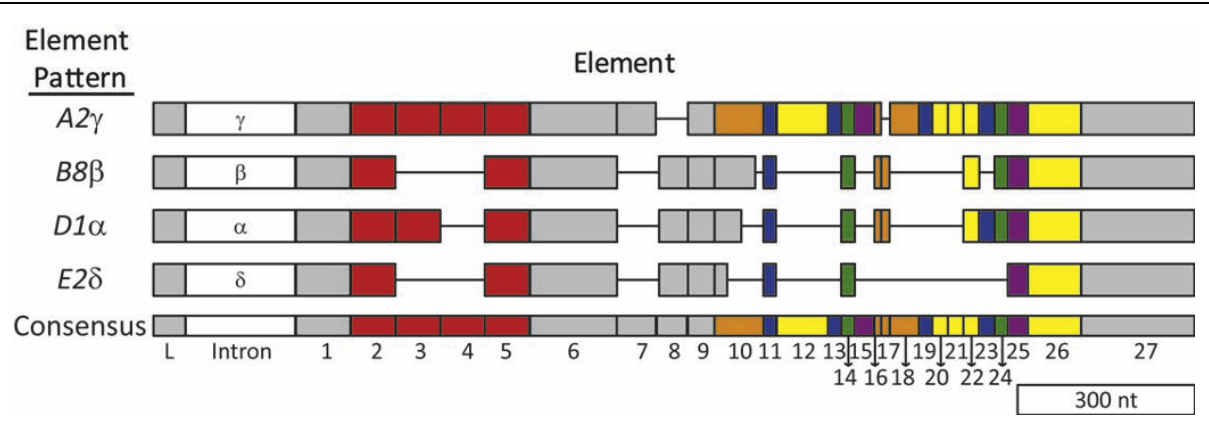

Figure 1 The Sp185/333 genes on $\mathbf{7 0 9 6}$ have four different element patterns. The genes are aligned according to the repeat-based alignment [15]. The genes have two exons and a single intron that is shown as a white box (not to scale). The first exon encodes the leader (L). The Greek letters indicate the intron type based on sequence analysis [15]. The second exon has large gaps (horizontal lines) inserted to optimize the alignment, which define blocks of sequence called elements (gray and colored boxes). The consensus of all possible elements is shown at the bottom. Variations in the presence or absence of elements defines element patterns $(A 2 \gamma, B 8 \beta, D 1 \alpha$, and $E 2 \delta$, which are abbreviated according to [15]). Elements that correlate with each of the six types of repeats are shown in different colors (type 1 in red; type 2 in blue; type 3 in green; type 4 in yellow; type 5 in purple; type 6 in orange; [15]). The figure is modified from [15]. 
shortcomings of shotgun assembly for these genes could be overcome by focusing on a single BAC insert, an easier task for a repeat-riddled region. We generated multiple candidate BAC assemblies with varying parameters to account for potential gene collapse or artificial duplication/expansion, and experimentally validated the assemblies to identify the optimal sequence. We present a unique perspective on sequence assembly and validation, particularly the need to adjust the assembly parameters locally, rather than using global parameters for the entire genome. This is the first report of a small cluster of six $S p 185 / 333$ genes in a $34 \mathrm{~kb}$ region located at one end of a $117 \mathrm{~kb} \mathrm{BAC}$ insert. The gene structure is consistent with that of previously characterized Sp185/333 genes; the coding region is contained within two exons, the second of which includes the mosaic pattern of elements [15]. All six genes are flanked on both sides by GA microsatellites and four of the genes have a GAT microsatellite in the $5^{\prime}$ flank. There is no correlation between linkage and sequence similarity, as the six genes on the BAC are no more similar to each other than to 121 unique genes that have been cloned and sequenced from three different animals [15]. The flanking regions of the genes that extend to the microsatellites exhibit significant sequence similarity. Three of the Sp185/333 genes are tandemly duplicated including their flanking regions and each repeated segment is delineated by microsatellites. The assembly of this region had to be validated by cloning and sequencing. The very high sequence similarity of the $S p 185 / 333$ genes, the flanking regions, and the positions of the flanking microsatellites may promote genomic instability and increase the rate of gene duplication of this family and/ or perhaps block homogenization resulting from gene conversion, thereby contributing to its extraordinary diversity.

\section{Methods}

\section{BAC library screening}

Two arrayed BAC libraries (Sp BAC genomic and Sp small BAC; http://www.spbase.org/SpBase/resources/ index.php) were screened for clones with $S p 185 / 333$ sequences [15]. The libraries differed in average insert sizes (Sp BAC genomic library inserts were $\sim 140 \mathrm{~kb}$, $25 \times$ genome coverage; Sp small BAC library inserts were $\sim 50-80 \mathrm{~kb}, 6.25 \times$ genome coverage) [30]. The libraries were screened with riboprobes synthesized from combinations of templates chosen from three Sp185/333 gene clones that included all known elements

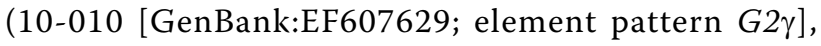
10-022 [GenBank:EF607640; element pattern $D 1 \alpha$ ], and 2-095 [GenBank:EF607756; element pattern E2 $\delta$ ]) [15]. The Sp small BAC library was screened as previously described for the Sp BAC genomic library [15].
Riboprobe synthesis and filter hybridization were performed as described in [31]. BAC clones with Sp185/333 sequence were obtained from Eric Davidson and Andrew Cameron at the California Institute of Technology.

\section{BAC insert isolation and PFGE analysis}

Bacterial cultures were grown at $37^{\circ} \mathrm{C}$ with chloramphenical and the BAC plasmids were isolated using the alkaline lysis protocol as described in [15]. The insert was released from the pBACe3.6 vector with NotI (New England Biolabs) digestion and analyzed by pulsed-field gel electrophoresis (PFGE) with 1\% Pulsed Field Certified Agarose (Bio-Rad Laboratories) gel in 0.5× TBE at $6 \mathrm{~V} / \mathrm{cm}$, and a ramped switch time from 1 to $15 \mathrm{sec}$ over 16 hrs. Gels were stained in $0.5 \mu \mathrm{g} / \mathrm{mL}$ ethidium bromide, destained and imaged under UV light. The MidRange pulsed-field gel (PFG) Marker I (New England Biolabs) was used to generate the standard curve to plot the BAC insert size.

\section{BAC sequencing}

A working draft sequence of BAC clone R3-3033E12 was generated as part of the $S$. purpuratus genome project [GenBank: AC178508.1] [32]. A randomly sheared subclone library was generated from BAC 178508 and end sequencing the subclones was performed at the Baylor College of Medicine (BCM) generating 1,886 traces by Sanger sequencing. Traces were deposited in the NCBI Trace Archive as a BCM center project SRHQ; TI number AC204781.3. The results reported here employ different methods (see following) than those used by the Baylor team to assemble the traces into a BAC insert sequence [GenBank: BK007096], which is hereafter called "7096".

\section{Assembly}

The 7096 sequence was assembled from the traces using the Whole-Genome Shotgun Celera Assembler [33]. Traces were converted into the format required by the Celera Assembler with the tarchive2ca tool, which is part of the A Modular Open Source tool suite http:// amos.sourceforge.net/ [33]. Assemblies were generated using default parameters, with the exception of varying unitigger error rates that ranged from the default of $1.5 \%$ to $0.2 \%$ in $0.1 \%$ decrements. Hawkeye [34] was used to view the assemblies graphically and to assess sequencing coverage. GenePalette [35] was used to annotate the 7096 assembly.

\section{Real-time quantitative PCR (qPCR) analysis of Sp185/333 genes on BACs}

qPCR was used to estimate the number of $S p 185 / 333$ genes on the BACs according to [19]. Primers used to 
Table 1 Primer locations in the exons or flanking untranslated regions ${ }^{1}$

\begin{tabular}{|c|c|c|c|}
\hline Primer $^{2}$ & Sequence & Strand $^{3}$ & Notes \\
\hline 5' UTR.1 & YTDTAGCATCGGAGAKACCT ${ }^{4}$ & $\mathrm{~S}$ & $5^{\prime}$ untranslated region of all genes \\
\hline $\mathrm{F} 2$ & AAGMGATTWCAATGAACKRCGAG & S & In the second exon $\sim 500 \mathrm{bp}$ from $5^{\prime}$ end of all genes \\
\hline F5 & GGAACYGARGAMGGATCTC & $\mathrm{S}$ & In the second exon $\sim 1.4 \mathrm{~kb}$ from the $5^{\prime}$ end of most genes \\
\hline F6 & GAAGAAGAAACTGATGCTGCC & $\mathrm{s}$ & In the second exon $~ 900 \mathrm{bp}$ from the start codon in all genes. \\
\hline LR1 & ATCRTYGCCATYSTGGCYG & AS & In the first exon $\sim 50 \mathrm{bp}$ from the start codon in all genes. \\
\hline R5 & AAATGGCGGTCCGATGRGTG & AS & In the second exon $\sim 800 \mathrm{bp}$ from the start codon in most genes \\
\hline R6 & GAGAMGAAGAAACTGATGCTGC & AS & In the second exon $\sim 900 \mathrm{bp}$ from the start codon in all genes. \\
\hline R9 & CGACATYTTCACCACYTDAAG & AS & In the second exon $\sim 1.5 \mathrm{~kb}$ from the $5^{\prime}$ end of most genes \\
\hline 3' UTR.1 & GTCGCYGAGGTGTAGAATTW & AS & $3^{\prime}$ end of all genes \\
\hline 3' UTF-1 & CGTCATAACCGTACCAAAGAC & S & $3^{\prime}$ end of some genes \\
\hline
\end{tabular}

'see also [15,19].

${ }^{2} \mathrm{~F}$, forward; $\mathrm{R}$, reverse.

${ }^{3} \mathrm{~S}=$ sense; $\mathrm{AS}=$ antisense.

${ }^{4} \mathrm{D}=\mathrm{A}, \mathrm{G}$, or $\mathrm{T} ; \mathrm{K}=\mathrm{G}$ or $\mathrm{T} ; \mathrm{Y}=\mathrm{C}$ or $\mathrm{T} ; \mathrm{R}=\mathrm{A}$ or $\mathrm{G} ; \mathrm{M}=\mathrm{A}$ or $\mathrm{C}$.

amplify the Sp185/333 genes were 5'UTF.1 and LR1 (Table 1). The BAC plasmid copy number in each reaction was quantified using primers $17 \mathrm{~F}$ and $18 \mathrm{R}$ (Table 2), which produced a single amplicon from the 7096 insert. Reactions were performed in duplicate under the following conditions: $95^{\circ} \mathrm{C}$ for $12 \mathrm{~min}$, followed by 40 cycles of $95^{\circ} \mathrm{C}$ for $15 \mathrm{sec}, 59^{\circ} \mathrm{C}$ for $30 \mathrm{sec}$, and $72^{\circ} \mathrm{C}$ for $30 \mathrm{sec}$. Melt curve analysis confirmed the amplification of a single product. The number of $S p 185 / 333$ genes on the BAC was determined by dividing the starting quantity of cloned Sp185/333 genes by the number of BAC plasmids in each reaction. Standard curves were generated from four 10-fold serial dilutions $\left(10^{7}-10^{4}\right.$ plasmids/reaction) using two cloned Sp185/333 genes (2-095, [GenBank: EF607756]; and a subclone of 7096 generated using primers $17 \mathrm{~F}$ and $18 \mathrm{R}$; Table 1). Two concentrations of BAC template DNA were used in the reactions.

\section{PCR and cloning}

Primers (Table 2) were designed with Primer Premier (Premier Biosoft International, Palo Alto, CA) based on an assembly of 7096 that was generated using $0.9 \%$ unitigger error rate. Amplicons of less than $5 \mathrm{~kb}$ were produced in reactions with $4-20 \mathrm{ng}$ of BAC DNA, 200 $\mathrm{nM}$ each primer, $200 \mu \mathrm{M}$ each dNTP, 1 unit (U) Paq5000 Taq (Stratagene, La Jolla, CA), and 1× company-supplied buffer. Samples were amplified under the following conditions: $3 \mathrm{~min}$ at $95^{\circ} \mathrm{C}$, followed by 25 cycles of $20 \mathrm{sec}$ at $95^{\circ} \mathrm{C}, 20 \mathrm{sec}$ at $51^{\circ} \mathrm{C}$ to $59^{\circ} \mathrm{C}$ and 10

Table 2 Intergenic primers

\begin{tabular}{|c|c|c|c|}
\hline Primer $^{1}$ & Sequence & Strand $^{2}$ & Notes $^{3}$ \\
\hline $1 \mathrm{R}$ & CGAAGATAAGTAATTGGT & AS & 300 bp 5'of each D1 gene \\
\hline $2 \mathrm{~F}$ & GTTCTGTITITAGTACCG & $\mathrm{s}$ & $\mathrm{RC}$ of $12 \mathrm{R}$, located $\sim 2.2 \mathrm{~kb} 3^{\prime}$ of all $D 1$ genes \\
\hline $6 \mathrm{~F}$ & TTGAGAGCTCGTCACGTG & $\mathrm{s}$ & $\sim 900 \mathrm{bp} 3$ ' of the D1-b gene \\
\hline $7 F$ & TGCAATCATTTACATATTACTGGTT & $\mathrm{S}$ & $\sim 800 \mathrm{bp} \mathrm{3}$ ' of the $A 2$ gene \\
\hline $9 F$ & GGGATTACATACCATACCGCA & $\mathrm{S}$ & $\sim 1 \mathrm{~kb} 3^{\prime}$ of the $B 8$ gene \\
\hline $11 \mathrm{~F}$ & ATCCTITGAAACAGCCCCTC & $\mathrm{S}$ & $\mathrm{RC}$ of $10 \mathrm{R}$, located $\sim 2.4 \mathrm{~kb} 3^{\prime}$ of the $\mathrm{D} 1-\mathrm{y}$ gene \\
\hline $13 \mathrm{~F}$ & TGGGAAATACTGACTGCC & $\mathrm{S}$ & $\mathrm{RC}$ of $5 \mathrm{R}$, located $\sim 2.7 \mathrm{~kb} 3^{\prime}$ of the $E 2$ gene \\
\hline $17 F^{4}$ & TITCCAATGTCCTTATTAACGACTTATA & $\mathrm{s}$ & qPCR primer with $18 \mathrm{R}^{1}$ \\
\hline $21 \mathrm{~F}$ & AATGTATTCGGCAGCGAGGT & $\mathrm{S}$ & $\sim 1 \mathrm{~kb} 3^{\prime}$ of the $D 1$ genes \\
\hline $5 R$ & GGCAGTCAGTATTTCCCA & AS & $\mathrm{RC}$ of $13 \mathrm{~F}$, located $\sim 1.1 \mathrm{~kb} 5^{\prime}$ of the $D 1-\mathrm{b}$ gene \\
\hline $8 \mathrm{R}$ & AAGCCTGCTGCTCAATCATC & AS & $\sim 1.2 \mathrm{~kb} 5^{\prime}$ of the $A 2$ gene \\
\hline $10 R$ & GAGGGGCTGTTTCAAAGGAT & AS & $\mathrm{RC}$ of $11 \mathrm{~F}$, located $\sim 1.1 \mathrm{~kb} 5^{\prime}$ of the $B 8$ gene \\
\hline $12 R$ & CGGTACTAAAAACAGAAC & AS & $\mathrm{RC}$ of $2 \mathrm{~F}$, located $\sim 1 \mathrm{~kb} 5^{\prime}$ of all D1 genes \\
\hline $14 \mathrm{R}$ & AAGTGGTGGTAGGCTCAGTAGTA & AS & $\sim 700 \mathrm{bp} 5^{\prime}$ of the $E 2$ gene \\
\hline $18 R^{4}$ & ATGATTCACAGGTTTGTTGCCTC & AS & qPCR primer with $17 \mathrm{~F}^{1}$ \\
\hline
\end{tabular}

${ }^{1} \mathrm{~F}$, forward; $\mathrm{R}$, reverse.

${ }^{2} \mathrm{~S}=$ sense; $\mathrm{AS}=$ antisense.

${ }^{3} \mathrm{RC}=$ reverse complement.

${ }^{4}$ These primers amplify a unique region used to quantify the copy number of BAC plasmids in qPCR reactions. 
sec to $2.5 \mathrm{~min}$ at $72^{\circ} \mathrm{C}$, followed by $3 \mathrm{~min}$ at $72^{\circ} \mathrm{C}$ and a $4^{\circ} \mathrm{C}$ hold. For amplicons longer than $5 \mathrm{~kb}$, each reaction consisted of 0.4 - 2 ng BAC DNA, $200 \mathrm{nM}$ each primer, $400 \mu \mathrm{M}$ each dNTP, 1 U Takara LA Taq (Takara Biosciences, Madison, WI) and $1 \times$ company-supplied buffer. Samples were amplified with the following conditions: 3 min at $94^{\circ} \mathrm{C}$ followed by 30 cycles of $30 \mathrm{sec}$ at $94^{\circ} \mathrm{C}$ and 5 to $10 \mathrm{~min}$ at $51^{\circ} \mathrm{C}$ to $65^{\circ} \mathrm{C}$, followed by $10 \mathrm{~min}$ at $72^{\circ}$ $\mathrm{C}$, and a $4^{\circ} \mathrm{C}$ hold.

Amplicons of regions surrounding the $D 1$ genes employed PCR reactions with $10 \mathrm{ng}$ of 7096 DNA, 500 $\mathrm{nM}$ each primer (1R and 2F; Table 2), $400 \mu \mathrm{M}$ each dNTP, 1 U PhusionTaq (New England Biolabs, Ipswich, MA), and $1 \times$ company-supplied buffer. Samples were amplified as follows: $30 \mathrm{sec}$ at $98^{\circ} \mathrm{C}, 25$ cycles of $10 \mathrm{sec}$ at $98^{\circ} \mathrm{C}, 20 \mathrm{sec}$ at $55^{\circ} \mathrm{C}$, and $2 \mathrm{~min}$ at $72^{\circ} \mathrm{C}$, followed by $5 \mathrm{~min}$ at $72^{\circ} \mathrm{C}$, and a $4^{\circ} \mathrm{C}$ hold. Amplicons were adenylated by adding $1 \mathrm{U}$ of Fisher Taq (Fisher Scientific, Pittsburgh, PA) to the reaction for $10 \mathrm{~min}$ at $72^{\circ} \mathrm{C}$ to facilitate amplicon cloning into pCR4-XL-TOPO (Invitrogen, Carlsbad, CA). Plasmid DNA (pCR4-XL-TOPO with 7096 fragment inserts) was isolated using the Wizard Plus Miniprep DNA Purification System (Promega, Madison, WI).

\section{Cycle sequencing}

Cycle sequencing reactions consisted of $165 \mathrm{ng}$ of plasmid DNA, $1 \mu \mathrm{M}$ of each primer, sequencing buffer (267 $\mathrm{mM}$ Tris base $\mathrm{pH}$ 9.0, $6.7 \mathrm{mM} \mathrm{MgCl}_{2}$ ), $1 \times$ dye terminator cycle sequencing (DTCS) Quickstart (Beckman Coulter, Fullerton, CA). Samples were amplified in an iCycler (Bio-Rad Laboratories) with the following conditions: 30 cycles of $20 \mathrm{sec}$ at $96^{\circ} \mathrm{C}, 20 \mathrm{sec}$ at $50^{\circ} \mathrm{C}$ and 20 sec at $60^{\circ} \mathrm{C}$, followed by a hold at $4^{\circ} \mathrm{C}$. DNA was precipitated and resuspended in CEQ Sample Loading Solution (Beckman Coulter). Samples were analyzed on a Beckman Coulter CEQ8000 using protocol LFR-a (Beckman Coulter) modified with a 10 second injection duration. Sequences were edited and assembled using Sequencher software (GeneCodes, Ann Arbor, MI).

\section{Bioinformatics}

Sequences were manually aligned using Bioedit [36]. Pairwise diversity was measured by pairwise distance analysis using MEGA v.4 [37] with pairwise deletion of gaps. Dot plots were generated using plotRep [38]. Microsatellites, interspersed repeats, and low complexity DNA sequences were identified by Repeatmasker (http://www.repeatmasker.org). Entropy was calculated as in [15].

\section{Results}

The disagreement between the number of $S p 185 / 333$ gene models in the $S$. purpuratus genome and our estimates of gene copy number may have resulted from a shortcoming of genome assembly methods, in which regions with similar sequences are artificially collapsed. Consequently, the gene models assembled in the genome may not be sequences of real genes, but rather, may be consensus sequences of multiple genes. Therefore, we analyzed the genomic organization of the Sp185/333 genes from the level of a finished BAC sequence. BAC sequences present a simpler computational problem for assembly because there is less sequence to assemble compared to an entire genome from a diploid, outbred animal, and because a BAC is sequence from a single haplotype. This was of particular relevance for the sea urchin, in which genomes have been shown to vary by 4-5\% among individuals [39] and the $S$. purpuratus genome assembly is a mosaic of both haplotypes [32].

\section{BACs with Sp185/333 sequence}

Screens of the large-insert BAC library [30] identified 75 clones that were positive for Sp185/333 sequence. Screens of the small-insert BAC library identified 46 positive clones (see [22], reviewed in [16]). Preliminary analysis of the BACs by PCR showed that the Sp185/ 333 genes were positioned in all possible orientations relative to each other and that many BACs had identical patterns of amplicons [15]. PCR, restriction digests and Southern blots of 11 BACs indicated four categories of genes based on the number of shared bands among the groups (data not shown). Two BACs were chosen for sequencing based on different patterns of $S p 185 / 333$ amplicons and the results for one BAC, 7096, are reported here.

\section{Assembling the 7096 BAC}

An initial sequence for 7096 [GenBank:AC204781] was assembled by the Baylor College of Medicine Human Genome Sequencing Center (BCM-HGSC) using the Phrap assembler [40] as part of the Atlas assembly system [41], with the traces from the randomly sheared subclone library [42]. To validate the sequence assembled by Phrap, the 7096 traces were reassembled with the Celera WGS assembler [43]. The Celera assembler was chosen based on its ability to optimize parameters for contig creation and its relative strengths for correctly assembling repeated regions [43].

Given the high similarity of the $S p 185 / 333$ genes, it was important to avoid collapsing two similar genes into a single gene and/or creating a non-existent hybrid gene. With this aim in mind, the unitigger error rate, which specifies the threshold of similarity at which two traces are assembled, was adjusted over a range of values. Decreasing the unitigger error rate prevents two or more similar genes from being collapsed into one. 
However, unitigger error rates that are too low could generate artificial genes from sequencing errors being treated as real single nucleotide polymorphisms (SNPs). In contrast, unitigger error rates that are too high would ignore real SNPs and incorrectly collapse two or more duplicated genes into one. Unitigger error rates ranging from the default of $1.5 \%$ plus a range of $1.2 \%$ to $0.2 \%$ in $0.1 \%$ decrements were used to generate 12 assemblies (Table 3).

A variety of parameters were compared among the 12 assemblies in addition to the BCM-HGSC assembly (Figure 2). Sizes of the assembled sequences ranged from $110,951-120,165 \mathrm{nt}$ in two to five unordered, unoriented scaffolds (Table 3 ). Each assembly consisted of a large scaffold of 94,782 - 109,918 nt (82 to $99 \%$ of an assembly) and one to four small scaffolds ranging in size from 1,033 - 16,978 nt (Figure 2). Assemblies with two scaffolds (5, 6,8 , and 9) were ordered and oriented based on the vector sequence. Assemblies consisting of three or more scaffolds were ordered and oriented by comparison to the single contig of the BCM-HGSC assembly. While the large scaffolds from each of the assemblies were nearly identical, the smaller scaffolds contained the Sp185/333 genes and varied significantly (Figure 2).

All 12 assemblies had three Sp185/333 genes that were identical among the assemblies: one with an $A 2$ element pattern, one with a $B 8$ element pattern and one with an $E 2$ element pattern (Figures 1, 2). In addition, each assembly had between one and three fully assembled $D 1$ genes, plus most assemblies showed a fragmented or poorly assembled $D 1$ gene (Table 3 ). The sequences of the $D 1$ genes varied among the assemblies (shown as yellow and green in Figure 2; see below). In each assembly, the gaps between the small scaffolds were flanked by the $D 1$ genes, which indicated that these genes were the source of the conflicts. Varying the unitigger rates altered the number and placement of the D1 genes, indicating that further analysis was necessary to obtain the accurate sequence of the Sp185/333 gene cluster. For clarity, the $D 1$ genes and fragments were given extended names according to their $5^{\prime}$ to $3^{\prime}$ order within assembly 9: $D 1$ yellow (D1-y), $D 1$ green $(D 1-\mathrm{g})$, and $D 1$ blue (D1-b) (Figure 2).

\section{Experimental validation of the assembled 7096 sequence} A two-fold approach was undertaken to validate the assemblies experimentally. First, PFGE and PCR were used to determine the size of the BAC insert and to confirm the existence and size of the three Sp185/333 genes present in all assemblies (Figures 1,2). Second, the region harboring multiple $D 1$ genes was analyzed more closely using PCR, cloning, sequencing, and restriction enzyme analysis. These results were used to reject incorrect assemblies, including the assembly generated by BCM-HGSC, and ultimately to define the correct 7096 sequence thereby enabling analysis of the Sp185/333 gene cluster. The 7096 insert size was estimated to be $117.6 \mathrm{~kb}$ by PFGE (data not shown), eliminating assemblies 2, 4, and 6 from further consideration as they were too short (Table 3). qPCR estimation of the $S p 185 / 333$ gene copy number indicated that there were 5.8 to $6.1 S p 185 / 333$ genes present (data not shown), which was in agreement with all of the assemblies, if whole genes plus fragments were considered. The remaining nine assemblies were evaluated in more detail.

Table 3 Varying assembly parameters affects the length, number of scaffolds, and Sp185/333 genes present in different assemblies

\begin{tabular}{|c|c|c|c|c|c|}
\hline \multirow[b]{2}{*}{ Assembly ${ }^{1}$} & \multirow[b]{2}{*}{ Unitigger rate (\%) } & \multirow[b]{2}{*}{ Length (nt) ${ }^{2}$} & \multirow[b]{2}{*}{ Scaffolds } & \multicolumn{2}{|c|}{ Sp185/333 } \\
\hline & & & & Genes & Gene Fragments \\
\hline 2 & 0.2 & 111,226 & 5 & 4 & 2 \\
\hline 3 & 0.3 & 120,165 & 4 & 5 & 3 \\
\hline 4 & 0.4 & 113,898 & 3 & 5 & 1 \\
\hline 5 & 0.5 & 117,017 & 2 & 5 & 1 \\
\hline 6 & 0.6 & 110,951 & 2 & 4 & 1 \\
\hline 7 & 0.7 & 116,484 & 3 & 5 & 1 \\
\hline 8 & 0.8 & 115,649 & 2 & 5 & 1 \\
\hline 9 & 0.9 & 117,014 & 2 & 5 & 1 \\
\hline 10 & 1.0 & 117,098 & 3 & 5 & 1 \\
\hline 11 & 1.1 & 115,591 & 3 & 4 & 2 \\
\hline 12 & 1.2 & 116,615 & 3 & 4 & 2 \\
\hline 15 & 1.5 & 115,620 & 4 & 4 & 2 \\
\hline $\mathrm{BCM}^{-\mathrm{HGSC}^{3}}$ & $\mathrm{n} / \mathrm{a}$ & 119,341 & 1 & 6 & 0 \\
\hline
\end{tabular}

${ }^{1}$ Assemblies 2-15 were generated with the Celera Assembler [33].

2excluding gaps.

${ }^{3}$ The sequence completed by BCM-HGSC (Genbank: AC204781.3) was assembled using Phrap [40] and Atlas [41]. 


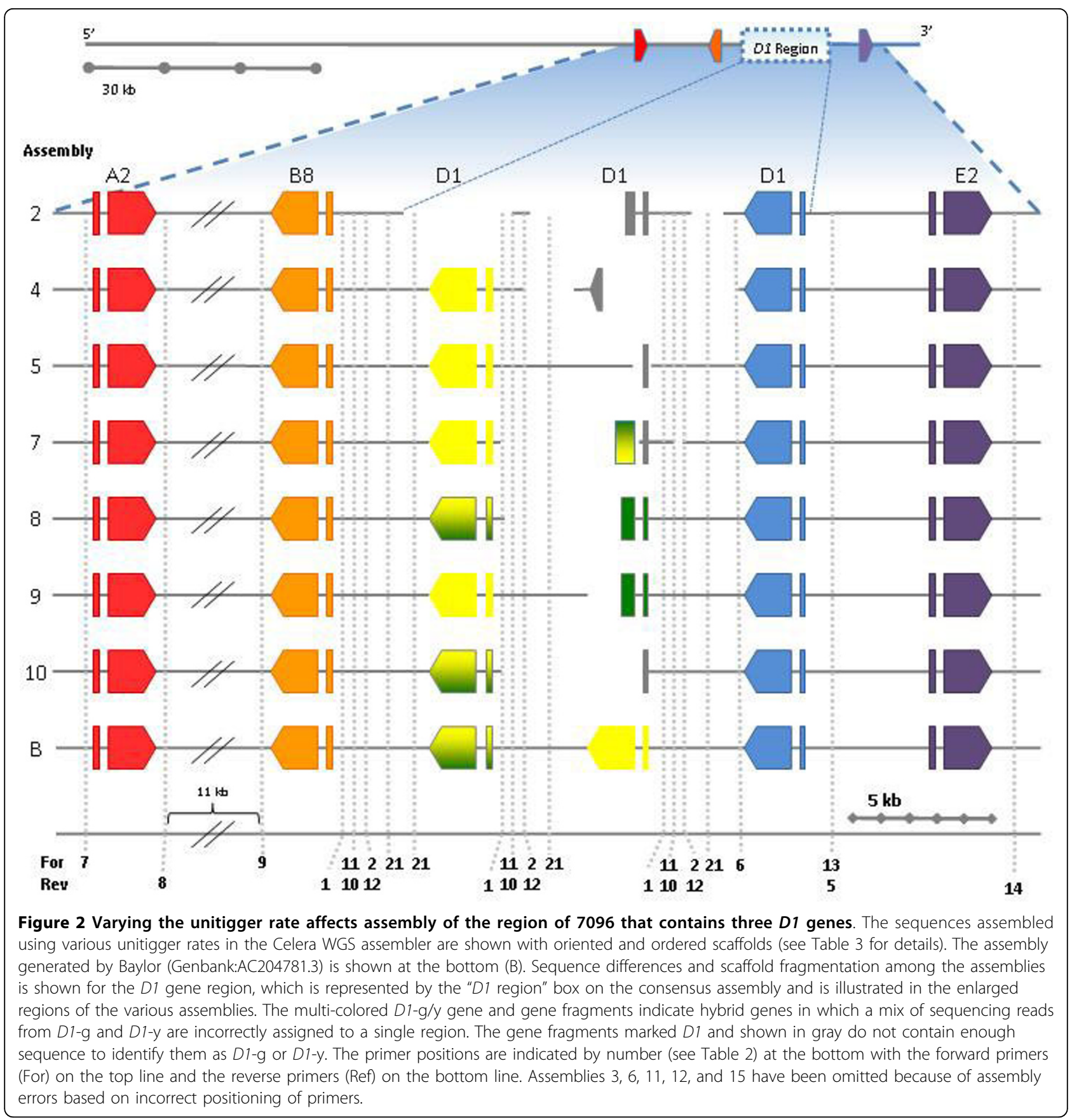

PCR was used to confirm the sizes of the non-D1 genes and to validate the region that included the $D 1$ genes, which varied among assemblies (Figure 2). Assembly 9 (Table 3; Figure 2) was chosen as the reference sequence for primer design because it consisted of only two scaffolds and was the second largest assembly $(117 \mathrm{~kb})$, suggesting that no genes had been collapsed or duplicated. Primers were designed to flank each of the genes and gene fragments, and PCR was used to confirm the sizes of the genes and their flanking regions.
Sizes of the amplified regions surrounding the $A 2, B 8$, and $E 2$ genes were consistent with the predicted sizes from all assemblies (Figure 3A), suggesting that these sequences were likely correct. PCR was also used to resolve the assembly of the $D 1$ region. When primers $6 \mathrm{~F}$ and $5 \mathrm{R}$ (Table 2) were used to amplify the D1-b gene plus flanking regions, an amplicon of $\sim 3.6 \mathrm{~kb}$ was obtained (Figure 3A). This size was different from that predicted in assemblies 11,12 , and 15 , eliminating them from further analysis. Primers $2 \mathrm{~F}$ and $1 \mathrm{R}$ (Table 2) 

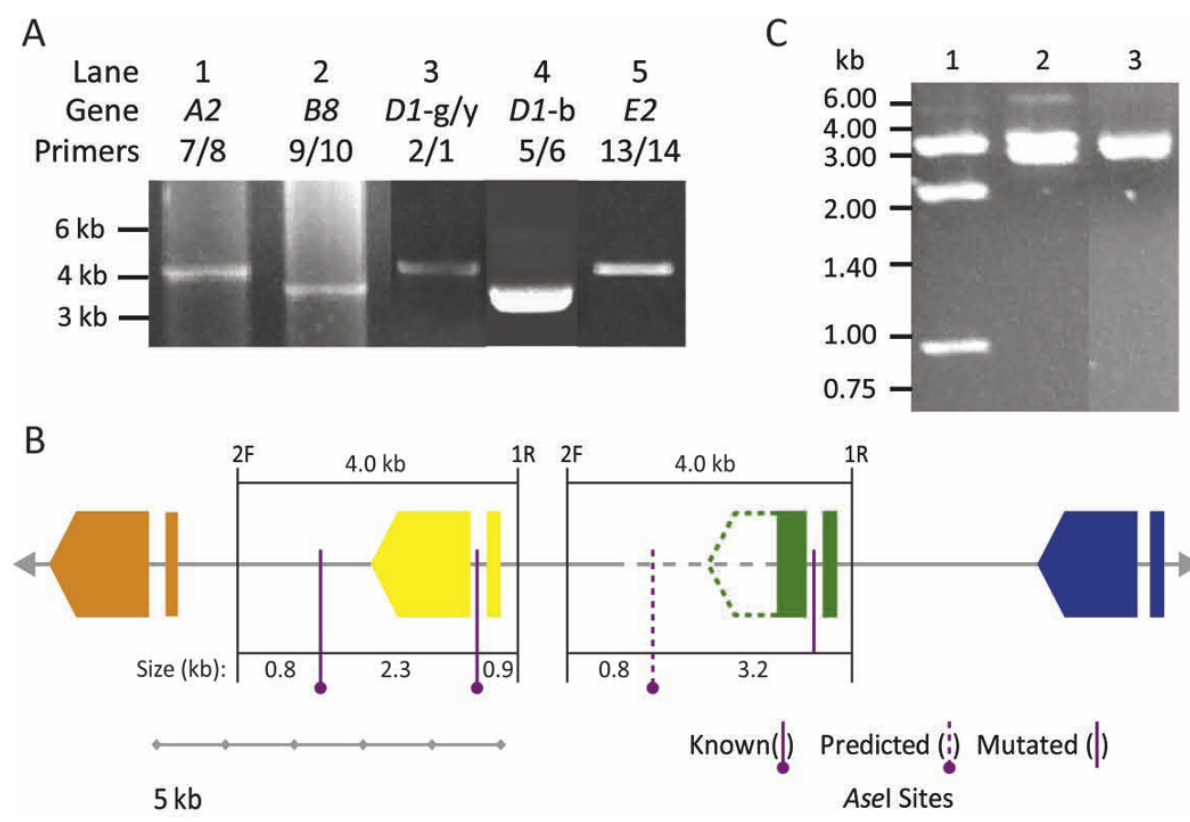

Figure 3 Experimental evidence supports assembly 9. A. PCR amplification confirms the sizes of the regions surrounding the $A 2, B 8, D 1-b$, and E2 genes. Amplicons in lanes 1 ( 4 kb), $2(\sim 3.6 \mathrm{~kb}), 4(\sim 3.6 \mathrm{~kb})$, and $5(\sim 4 \mathrm{~kb})$, correspond to the sizes of the A2, B8, D1-b, and E2 genes plus their flanking regions according to sizes predicted in all the candidate assemblies (see Figure 2). A single amplicon of $\sim 4 \mathrm{~kb}$ (lane 3 ) was generated from primers predicted to amplify each D1-g, and D1-y genes plus flanking regions. See Table 2 and Figure 2 for primer information. B. Diagram of a region of assembly 9 showing the D1 genes (B8, orange; see also Figure 2). The subcloned regions of 7096 containing D1 genes (amplified with primers $2 \mathrm{~F}$ and $1 \mathrm{R}$; see Table 2 and Figure 2) are indicated. The assembled sequence for these subclones contains either one (D1-y) or two (D1-g) Asel restriction sites (purple lines). One of the Asel sites in the D1-g gene is mutated by a SNP. Because of the gap in assembly 9, which includes this region (dashed line), one of the Asel sites is predicted (dashed purple line) based on sequence similarity with the D1-y subclone. C. A SNP obliterates an Asel restriction site and differentiates D1-y and D1-g genes. PCR amplicons using 2F and 1R primers produce $4 \mathrm{kB}$ fragments. When digested with Asel the clones containing a D1-y gene could be differentiated from those with a D1-g gene. Lane 1, D1-y gene (4.2 kb, $2.3 \mathrm{~kb}$, and 0.9 kb). Lane 2, D1-g gene (4.2 kb and $3.2 \mathrm{~kb})$. Lane 3, vector without insert has one Asel site (4 kb).

annealed in two locations: flanking both the $D 1-y$ and D1-g genes (Figures 2, 3B), which included the gap between the two scaffolds. However, a single amplicon of $\sim 4 \mathrm{~kb}$ (Figure $3 \mathrm{~A}$ ) suggested that there was a single $D 1$ gene, either $D 1$-y or $D 1$-g, although it did not rule out the possibility that both $D 1$-y and $D 1$-g genes were present and that the $2 \mathrm{~F}$ and $1 \mathrm{R}$ primers amplified two fragments of the same size. To resolve the $D 1$ gene region, amplicons with $D 1$-y or $D 1$-g genes using the $2 \mathrm{~F}$ and $1 R$ primers were cloned (Table 2; Figure $3 B$ ). Each $2 \mathrm{~F} / 1 \mathrm{R}$ subclone had a $4 \mathrm{~kb}$ insert with a single $D 1$ gene plus a $\sim 200$ bp $5^{\prime}$ flanking region and a $\sim 2 \mathrm{~kb} 3^{\prime}$ flanking region. To differentiate between the $2 \mathrm{~F} / 1 \mathrm{R}$ subclones with either the $D 1$-g or the $D 1$-y gene, the sequences from the assemblies still under consideration $(5,7,8,9$, 10) plus that from BCM-HGSC were inspected more closely. The Celera assembler did not fully assemble D1$\mathrm{g}$ gene and the fragment varied in length from 30 to $840 \mathrm{nt}$ in different assemblies, whereas the BCM-HGSC assembly positioned the $D 1-y$ gene to the $3^{\prime}$ side of a $D 1$ gene that was a mix of nucleotides from both $D 1-\mathrm{g}$ and $D 1$-y (Figure 2). Based on the sequence of assembly
9, the D1-g fragment and the corresponding region of $D 1$-y were $99.8 \%$ identical over 840 nt with only two SNPs. An AseI site (ATTAAT) in the D1-y intron was obliterated in the D1-g intron by a SNP (ATTAAC) (Figure 3B). This SNP was confirmed by digestion of the subclones (Figure $3 \mathrm{C}$ ) such that two patterns of bands were observed. This was consistent with the presence of two different $D 1$ genes (D1-y and $D 1$-g) in addition to $D 1$-blue and the sequence from assembly 9 .

To complete the sequence of the $D 1$-g gene, which was missing at least part of the $3^{\prime}$ end in most of the assemblies, a $2 \mathrm{~F} / 1 \mathrm{R}$ subclone containing the $D 1$-g gene was sequenced at $5.8 \mathrm{X}$ coverage with gene specific primers previously designed for sequencing Sp185/333 transcripts and cloned genes (Table 2, see also $[15,19]$ ). These results showed that assembly 7 and that generated by BCM-HGSC did not have a correct $D 1$-g gene and were eliminated from further analysis. The $5^{\prime}$ end of the $D 1-y$ gene, which was a region that varied among assemblies, was also sequenced at $2.94 \times$ coverage with gene specific primers (Table 1) and results for a correct $D 1$-y gene were not consistent with assemblies 8 and 
10, which were also eliminated. These results showed that the $D 1$-g gene shared an average $99.7 \%$ similarity with $D 1-\mathrm{y}$ and $D 1-\mathrm{b}$, giving insight into the difficulties for assembling this region of the BAC. The $D 1$ genes from assemblies 5 and 9 had 100\% identity with the experimentally confirmed $D 1-y$ and $D 1$-g sequences. These two assemblies were nearly identical. The $2 \mathrm{~kb}$ gap between the two scaffolds was filled by sequencing $(1.97 \times$ coverage) a $2 \mathrm{~F} / 1 \mathrm{R}$ clone containing the $D 1$-g gene that spanned the gap. The resulting sequence connected the two scaffolds to complete a final assembly (Figure 4).

\section{Analysis of the assembled 7096 sequence Sp185/333 genes on 7096}

The 7096 assembly contained six $S p 185 / 333$ genes with the following element patterns: one $A 2 \gamma$, one $B 8 \beta$, one $E 2 \delta$, and three $D 1 \alpha$ genes (Figure 1; Greek letters represent the intron class based on sequence variations; see [15]). The genes varied in size from 1286 to $1881 \mathrm{nt}$ and were of identical structure to that reported previously: two exons and one intron $[15,19]$. The genes were located within a $34 \mathrm{~kb}$ region at the $3^{\prime}$ end of the assembled insert (Figure 4) with the $A 2$ gene separated from the rest by $14 \mathrm{~kb}$. The remaining five genes were clustered within $20 \mathrm{~kb}$, with intergenic regions of $3.2 \pm$ $0.2 \mathrm{~kb}$. The three $D 1$ genes and the $B 8$ gene were adjacent to one another in the middle of the cluster and were all oriented in the same direction, whereas the genes at the edges of the cluster, $A 2$ and $E 2$, were oriented in the opposite direction (Figure 4).

The assembled BAC sequence surrounding the Sp185/ 333 genes was investigated for the basic signatures of transcriptional control, including the TATA box, and polyadenylation signal. In five of the six Sp185/333 genes a TATAAA sequence was located 106 nt $5^{\prime}$ of the start codon, however, there was a TATACA sequence in same position for the $D 1-g$ gene. A polyadenylation signal (AATAAA) was identified 175 to $267 \mathrm{nt} 3^{\prime}$ of the stop codon in four of the six genes. The $D 1-\mathrm{b}$ and $D 1$-g genes had a SNP that altered their polyadenylation sequences to ATTAAA and AATATA, respectively. Both the
TATAA box and the polyadenylation site for the D1-g gene were non-canonical sequences, however the effect of these sequence variations on expression is unknown.

\section{Sp185/333 sequence diversity}

To understand the relationships among the clustered Sp185/333 genes, their pairwise sequence diversity was calculated [37] using pairwise gap deletion, which removes positions in which one of the sequences has a gap, to account for variations in element pattern. The mean diversity among the six $S p 185 / 333$ genes was 0.072 (Figure 5). The $A 2$ gene was the most divergent relative to the other $S p 185 / 333$ genes on the BAC, whereas the $D 1$ genes were almost identical (Table 4 ). The introns were generally more diverse although the introns from the clustered $D 1$ genes were highly similar.

The diversity of the six clustered $S p 185 / 333$ genes were compared to 121 unique $S p 185 / 333$ genes collected randomly from three individual sea urchins for which the relative genomic organization was unknown [15]. The clustered genes on 7096 were slightly more diverse (mean diversity score of 0.072 ) than genes isolated from the three animals (diversity scores of 0.057 to 0.063) (Figure 5). Because the diversity analysis is influenced by element pattern, and previous data suggested that genes and mRNAs with the same element patterns have nucleotide sequences that are more similar than sequences that do not share element patterns [15,19], the diversity scores were calculated for the $D 1$ genes from each of the four sources (three animals and 7096). The three clustered $D 1$ genes were slightly more similar to each other than to $D 1$ genes isolated from different animals (mean diversity of 0.003), but the differences were not significant (Figure 5). This result was unexpected, given the possible effects of homogenizing forces (e.g. unequal crossing over and gene conversion) and led us to evaluate the distribution of specific element sequences among the genes. Individual elements of the clustered genes were investigated to determine whether they were more likely to share elements with identical sequence compared to elements from genes randomly isolated from other sea urchins. Results indicated that

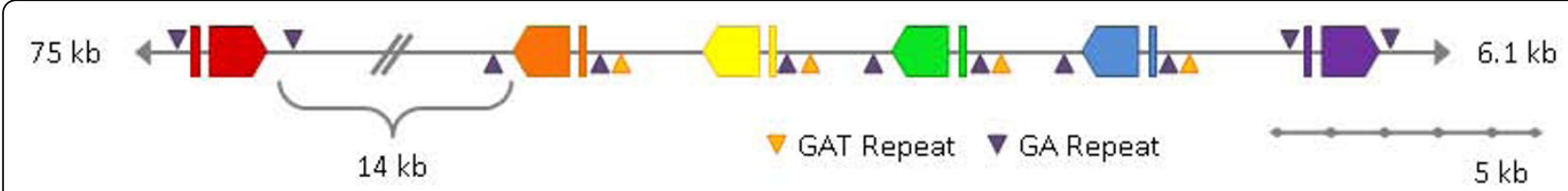

Figure 4 The experimentally validated assembly of 7096 contains six Sp185/333 genes. The finished assembly and sequence of the region in 7096 containing the Sp185/333 genes is shown after experimental confirmation by PCR, PFGE, Asel digests, and sequencing subclones. The BAC contains six Sp185/333 genes: one A2 gene, one B8 gene, three D1 genes, and one E2 gene (see Figure 1 for element pattern information). All are located at the $3^{\prime}$ end of the BAC insert. Gene orientations are indicated and spacing is to scale unless otherwise noted. GA microsatellites are shown flanking each gene and GAT microsatellites are shown to the $5^{\prime}$ side of B8 and the three D1 genes. 


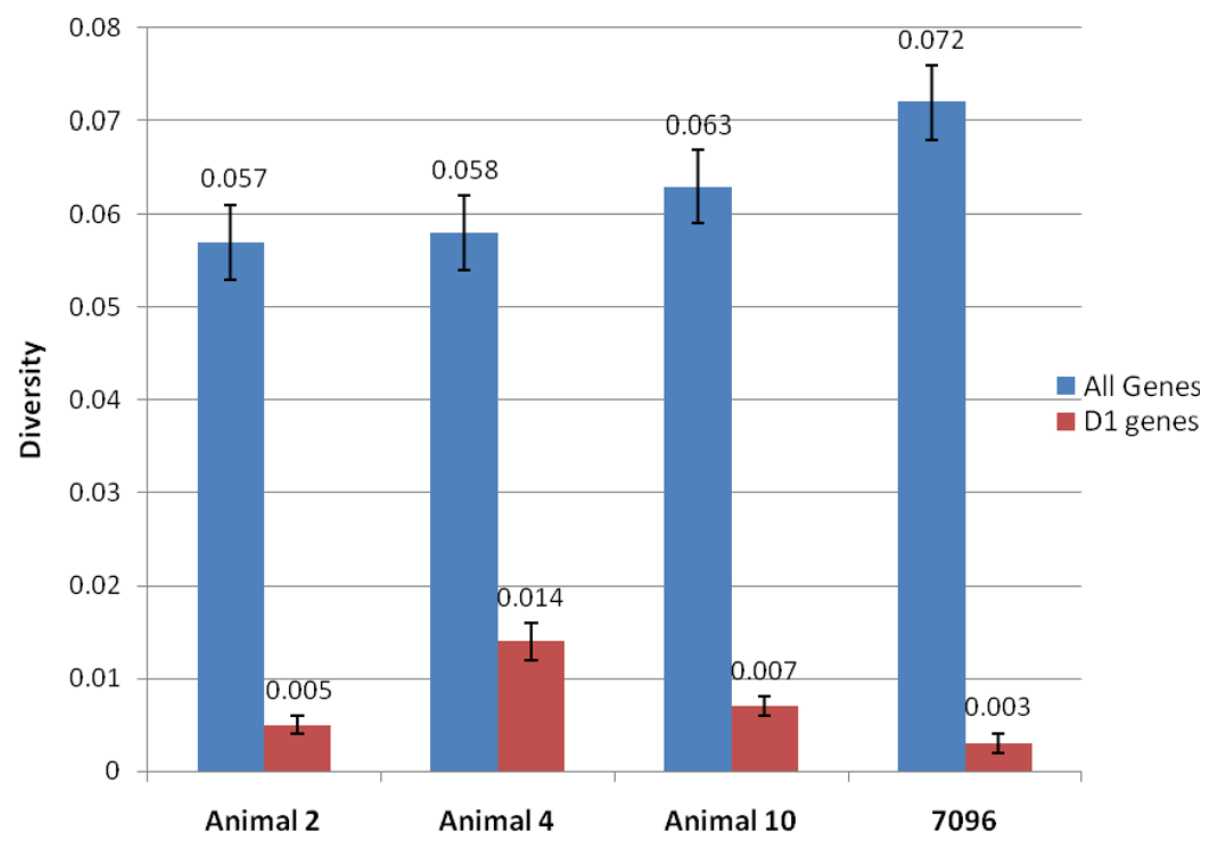

Figure 5 The Sp185/333 genes from 7096 are equally diverse as those randomly isolated from three animals. Mean pairwise diversity scores of the six Sp185/333 genes from 7096 are compared to other Sp185/333 genes previously isolated from three other sea urchins (blue bars; 29 genes from animal 4, 87 genes from animal 2, and 49 genes from animal 10 [15]). The D1 genes (9 genes from animal 4, 20 genes from animal 2, 6 genes from animal 10, and 3 genes from 7096) were analyzed separately (red bars).

there was no correlation between shared element sequences and tight clustering of the genes (Figure 6).

\section{Conserved flanking regions}

Each of the Sp185/333 genes on 7096 was flanked by GA microsatellites (Figure 4). The GA microsatellite

Table 4 Pairwise diversity of the Sp185/333 genes ${ }^{1}$

\begin{tabular}{|c|c|c|c|c|c|c|}
\hline & & D1-y & D1-g & D1-b & B8 & $A 2$ \\
\hline & D1-g & 0.004 & & & & \\
\hline \multirow[t]{9}{*}{ Full-length gene } & D1-b & 0.003 & 0.003 & & & \\
\hline & B8 & 0.071 & 0.072 & 0.071 & & \\
\hline & $A 2$ & 0.103 & 0.103 & 0.103 & 0.103 & \\
\hline & E2 & 0.087 & 0.088 & 0.087 & 0.082 & 0.096 \\
\hline & D1-g & 0.004 & & & & \\
\hline & $D 1-b$ & 0.004 & 0.003 & & & \\
\hline & B8 & 0.060 & 0.061 & 0.060 & & \\
\hline & $A 2$ & 0.081 & 0.082 & 0.081 & 0.077 & \\
\hline & E2 & 0.057 & 0.059 & 0.057 & 0.054 & 0.078 \\
\hline \multirow[t]{5}{*}{ Intron } & D1-g & 0.002 & & & & \\
\hline & D1-b & 0.002 & 0.005 & & & \\
\hline & B8 & 0.101 & 0.103 & 0.101 & & \\
\hline & $A 2$ & 0.168 & 0.165 & 0.168 & 0.175 & \\
\hline & E2 & 0.172 & 0.176 & 0.172 & 0.166 & 0.139 \\
\hline
\end{tabular}

'Diversity scores were generated using MEGA [37] with pairwise comparisons of full-length sequences, exon 1 plus exon 2 without the intron, and the intron alone. positioned on the $5^{\prime}$ side of each gene was located $\sim 430$ nt from the start codon and ranged in size from $30-60$ repeats (Figure 7). The GA microsatellite on the $3^{\prime}$ side of each gene had 140 - 165 repeats and was located $\sim 300$ - 350 nt from the stop codon, except for $A 2$, in which the GA microsatellite was $\sim 700$ nt $3^{\prime}$ of the stop codon. GAT microsatellites, with $\sim 37$ - 60 repeats were located $\sim 550-\sim 600$ nt $5^{\prime}$ of the start codon of $B 8, D 1$ g, D1-b, and D1-y (Figure 4). In general, each gene was flanked by GA microsatellites and a subset of the genes had 5' GAT microsatellites.

In addition to microsatellites, fragments of transposable elements were detected among the clustered Sp185/ 333 genes and were associated with two of the GA microsatellites. A portion (139 nt; 5.9\%) of a Gypsy10long terminal repeat (LTR)_S LTR element [GenBank: AAGJ02039135.1] was positioned 684 nt $3^{\prime}$ of the $A 2$ gene in a region between the gene and the flanking $3^{\prime}$ GA microsatellite (Figure 8). It was $50 \mathrm{nt}$ to the $5^{\prime}$ side of, and extended $90 \mathrm{nt}$ into the GA repeat, constituting about half of the repeat. Three tandem, incomplete Tc1N1_SP DNA transposon elements [44], representing $48 \%, 13 \%$, and $25 \%$ of the Tc1 consensus sequence, were positioned $522 \mathrm{nt} 5^{\prime}$ of the start codon for the $E 2$ gene, and $50 \mathrm{nt}$ upstream of the $5^{\prime}$ GA microsatellite (Figure 8). It is not known whether these transposable elements may be involved with diversification of the Sp185/333 gene family. 


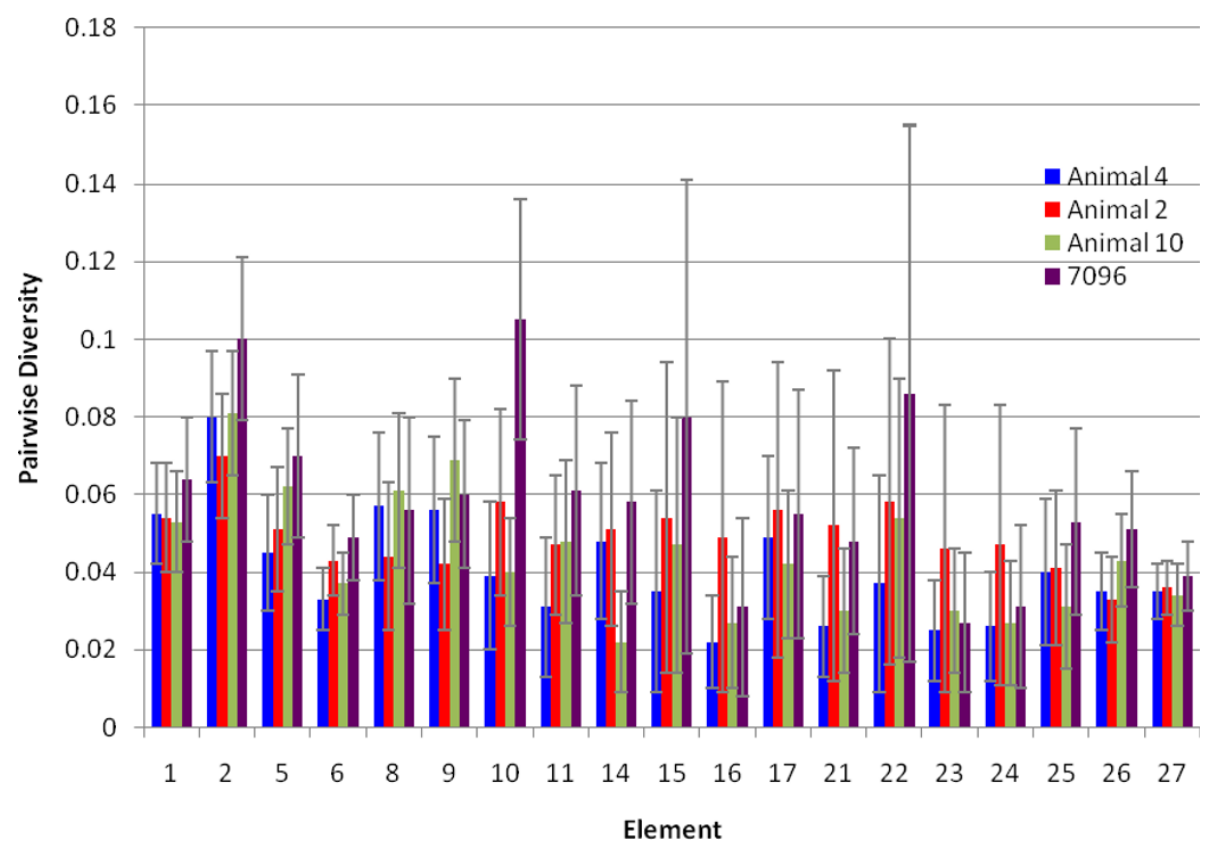

Figure 6 The element sequence diversity for the Sp185/333 genes clustered on 7096 is not different from the element diversity for the Sp185/333 genes with unknown genomic organization. Unique Sp185/333 genes from three sea urchins previously isolated (see legend for Figure 5, [15]) and the six genes from 7096 were aligned according to the repeat-based alignment (as in Figure 1, [15]). Genes from individual animals and those from the BAC were used to calculate pairwise diversity scores for each element in MEGA [37]. Average diversity scores and the standard deviations are shown. Elements that were not present in a majority of the sequences were omitted from the analysis.

Based on the presence of microsatellites and LTRs and the conserved distances between these repeats relative to the $5^{\prime}$ and $3^{\prime}$ ends of the genes, the level of sequence conservation was calculated among the genes and among the proximal and distal flanking regions with respect to the GA microsatellites. Genes and flanking regions were divided into five regions: the gene including the intron, the regions between each exon and the respective flanking GA microsatellite (proximal regions 2 and 3 in Figure 9A), and the regions outside of each GA microsatellite (distal regions 1 and 4 in Figure 9A). The pairwise diversity for each of these regions was calculated for all pairs of genes and regions. The microsatellites were not included in the analysis because variations in copy number precluded a robust alignment. Three regions were relatively conserved; the proximal flanking region 2 (between the 5' GA microsatellite and the start codon [average diversity $=0.115$; Figure 9A]) and region 3 (between the stop codon and the $3^{\prime}$ GA microsatellite [average diversity $=0.164$ ]), and the gene sequences themselves (average diversity $=0.084$ ). These three regions had relatively low diversity scores indicating sequence conservation between the microsatellites including the genes and their proximal flanking regions.

The pairwise diversity scores for the distal regions outside of the flanking GA microsatellites (regions 1 and
4, Figure 9A) defined three categories of gene diversity: high, hybrid, and low. The high diversity category for the distal regions included the pairwise diversity scores between either $A 2$ or $E 2$ and each of the other genes. Results showed a sharp increase in the sequence diversity between the proximal and distal flanking regions with respect to the GA microsatellites. This indicated that the proximal flanking sequences were generally more similar to each other than the distal flanking regions were to each other. The hybrid diversity category included pairwise comparisons between $B 8$ and each of the $D 1$ genes with respect to the two distal regions (Figure 9A). There was low diversity in region 1 (average diversity $=0.051$ ) and high diversity in region 4 (average diversity $=0.548$ ). Regions 1 and 2 for the $B 8$ gene were conserved with respect to all of the $D 1$ genes because that side of $B 8$ was adjacent to the GAT microsatellite and part of the intergenic region oriented towards the $D 1$-y gene (see Figure 4 ). On the other hand, regions 3 and 4 of the $B 8$ gene had divergent sequence with respect to the corresponding $D 1$ gene regions, and were part of the intergenic region oriented towards the $A 2$ gene. The $B 8$ gene therefore represented an interesting hybrid of conserved and divergent flanking regions. The low diversity category included pairwise comparisons among the three D1 genes, which had low scores in all regions (Figure 9A). 


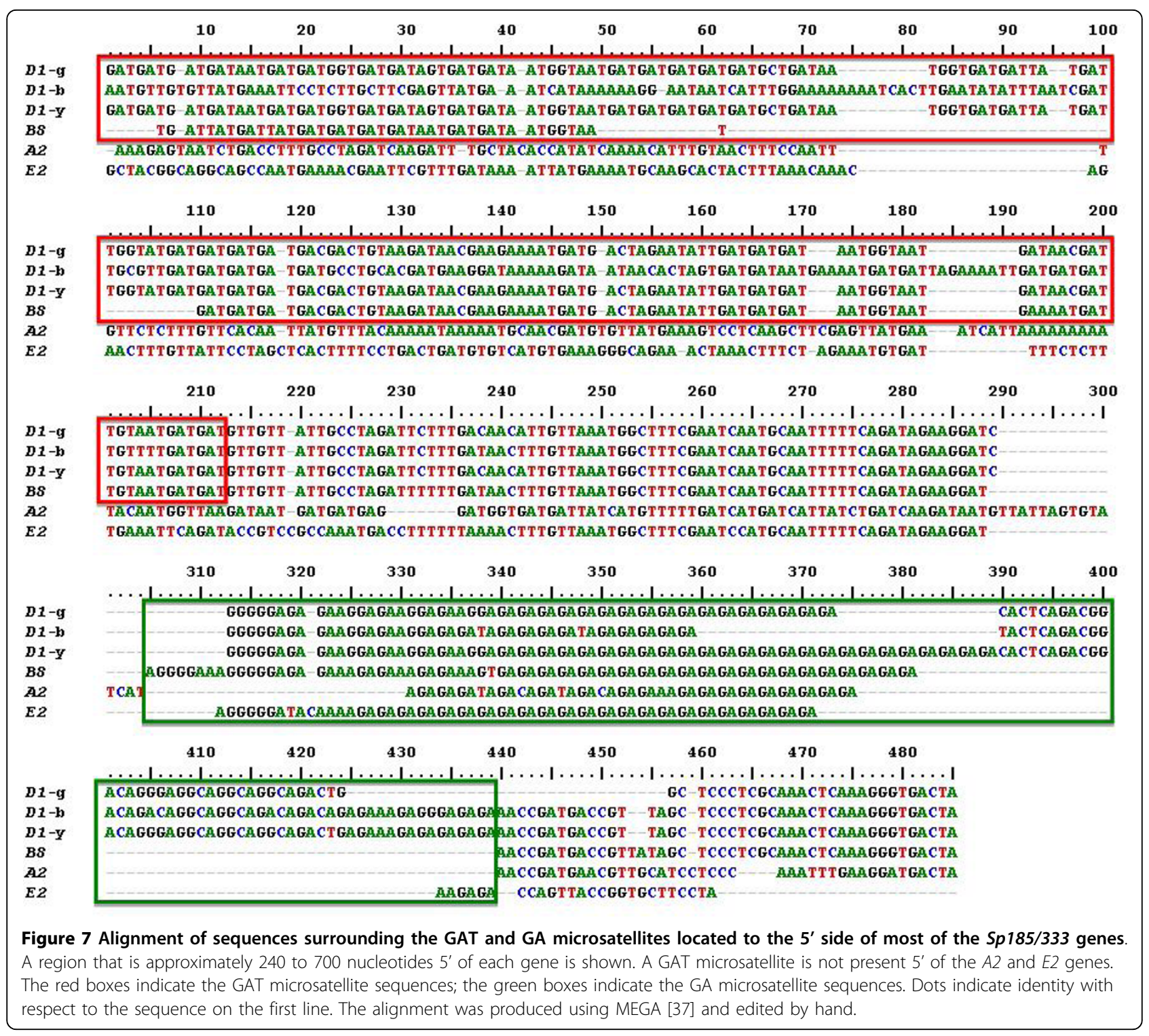

The patterns of sequence diversity among the genes and the flanking regions were analyzed more closely by calculating the average diversity (using the entropy equation) over a sliding $30 \mathrm{bp}$ window (Figure 9B). The diversity of all six sequences indicated that the genes, as well as the proximal flanking regions (2 and 3) were relatively conserved, and that the sequences diverged sharply distal to the GA microsatellites (regions 1 and 4). When only the $D 1$ genes were analyzed, they showed much greater identity in all regions compared to the result that included all of the genes (Figure 9B). The D1 genes were almost identical, with slightly less identity in the proximal flanking regions (2 and 3 ) and somewhat less identity in the distal flanking regions ( 1 and 4$)$. In all cases, the microsatellites marked the boundaries between the more conserved and less conserved flanking sequence.
The low diversity surrounding the $D 1$ genes suggested that conserved sequence may extend beyond the distal flanking regions that were analyzed. A dot plot of the BAC sequence that included the Sp185/333 gene cluster was used to determine the extent of conservation in the intergenic regions between all of the genes, and the $D 1$ flanking regions in particular (Figure 10). Results were in agreement with the diversity (entropy) scores and showed conserved sequence of the genes and the proximal flanking regions that were bounded by the GA microsatellites. Furthermore, the dot plot also showed large, or segmental, tandem duplications that included each of the $D 1$ genes and their intergenic sequences (Figure 10). The segmental duplication was $\sim 13.5 \mathrm{~kb}$ in total and consisted of three equal tandem segments each with a single $D 1$ gene and its flanking regions 


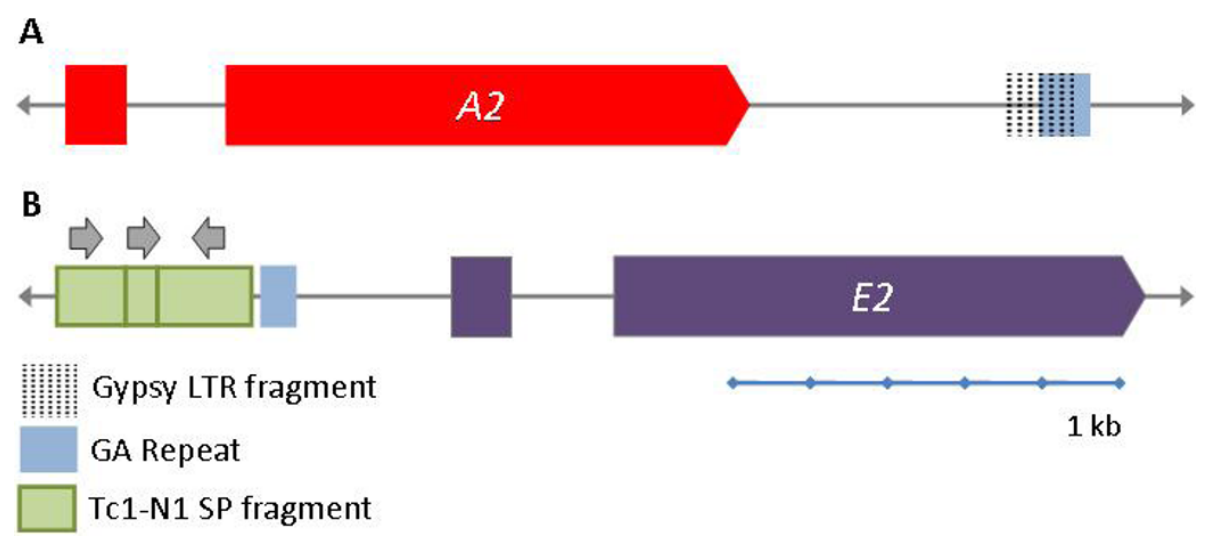

Figure 8 Transposon fragments are present in the flanking regions for the $\boldsymbol{A} \mathbf{2}$ and $\boldsymbol{E} 2$ genes. A. Gypsy10-long terminal repeat (LTR)_S fragment. The LTR [GenBank:AAGJ02039135.1] is represented by $139 \mathrm{nt}$ of $2430 \mathrm{nt}$ of the consensus sequence. It is present $684 \mathrm{nt}$ to the 3 ' side of $A 2$ and continues $87 \mathrm{nt}$ into the GA microsatellite. B. Three Tc1-N1 SP transposon fragments. Transposon fragments [44] (267 nt, 75 nt, and $140 \mathrm{nt}$ of $553 \mathrm{nt}$ consensus sequence) are present in tandem and positioned $453 \mathrm{nt} 5^{\prime}$ of E2 and $70 \mathrm{nt} 5^{\prime}$ of the GA microsatellite. Fragment orientation is indicated with arrows.

(Figure 10). Each duplication included $\sim 700 \mathrm{nt} 5^{\prime}$ and $\sim 2.3 \mathrm{~kb} 3^{\prime}$ of each $D 1$ gene and was bounded by GAT microsatellites. The sequence conservation of the $5^{\prime}$ flanking region of the $B 8$ gene, noted from the low pairwise diversity scores, appeared to be part of the segmental duplication. However, because the $B 8$ gene had a different element pattern from the duplicated $D 1$ genes, and because the conserved 3 ' flanking region of $B 8$ only extended $330 \mathrm{nt}$ to the GA microsatellite, we speculate that the putative duplication of the $B 8$ gene mediated by the GA microsatellites was adjacent to the segmental duplication that included $D 1$ genes but was not part of it. In general, the patterns of sequence conservation and positions of microsatellites suggest multiple mechanisms of sequence duplication and diversification within the Sp185/333 gene family.

\section{Discussion}

The data presented here are the first finishing-level sequence of a small cluster of $S p 185 / 333$ genes on a BAC insert. Multiple assemblies were generated with varying parameters to account for potential gene collapse or artificial duplication/expansion, which is a significant problem for regions with shared sequence or many repeats. The optimal assembly was verified by molecular biology techniques. We describe a unique perspective on sequence assembly and validation, particularly the local adjustment of assembly parameters to account for regions with repeats that are often misassembled when global parameters are used to assemble whole genomes. Six Sp185/333 genes are clustered within $34 \mathrm{~kb}$ and have an intron/exon structure that is consistent with previous reports $[15,19]$. Each of the three $D 1$ genes is positioned within tandemly duplicated segments that include the intergenic regions and is delineated by GAT microsatellites (Figure 11). We speculate that these microsatellites are involved with this recent duplication event and that the SNPs within segments are due to subsequent sequence diversification. Furthermore, all six genes on the BAC display significant similarity within the coding regions and the $5^{\prime}$ and $3^{\prime}$ proximal flanking regions, which are bounded by GA microsatellites, suggesting duplications of these shorter regions (Figure 11). There may be multiple mechanisms that operate in this gene cluster and that 1) may employ microsatellites to promote sequence diversification, 2) may also block sequence homogenization of the region resulting from gene conversion, and 3) may prevent the generation of gene fragments and pseudogenes. Together, this would contribute to and maintain the extraordinary diversity of this gene family.

\section{Microsatellites and sequence diversification}

Microsatellites are common in the genomes of most organisms, although their importance in function and evolution has been debated for years [45-47]. Microsatellites have been associated with regions of increased recombination in a number of organisms, including yeast [48] and, to a lesser extent, mammals [49-51]. Microsatellites have also been associated with increased genomic diversity by promoting sequence duplications, gene conversion, crossovers, and generating local recombination hotspots [45,48-50,52,53]. A novel segmental duplication mechanism has been reported wherein duplications are generated by template switching between microsatellites [54] and appear to stimulate recombination in plasmids [55-58]. The 


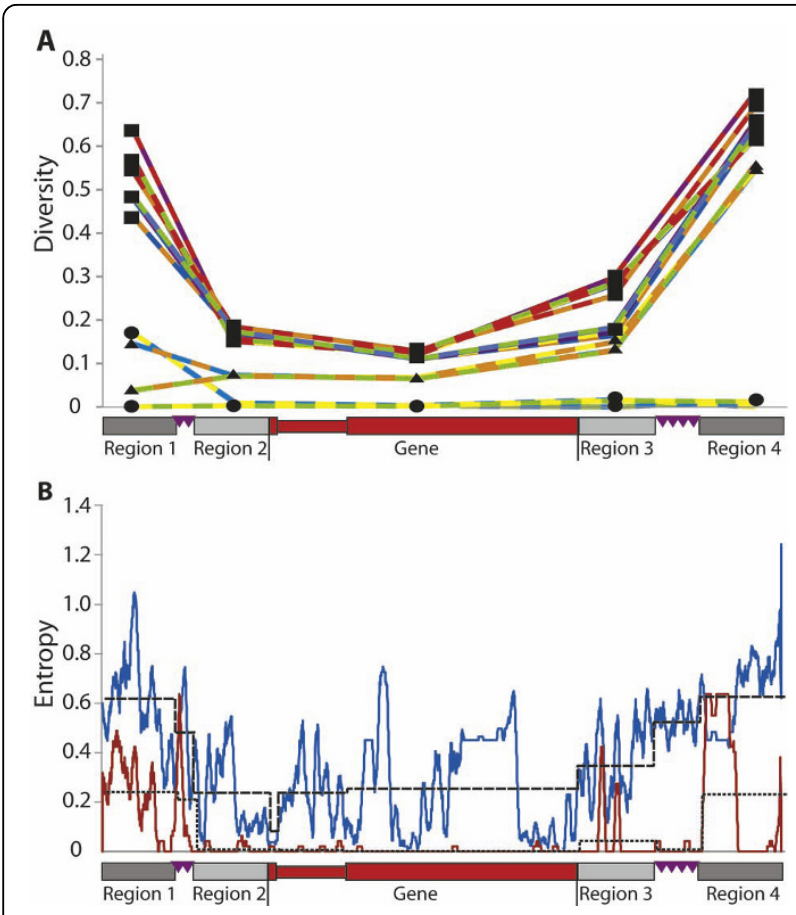

Figure 9 Microsatellites border the conserved sequence flanking the Sp185/333 genes. A. Pairwise diversity of Sp185/333 genes and flanking regions. Pairwise diversity was calculated among five regions (gene and four flanking regions) in MEGA [37]. The Sp185/333 gene (on the $x$-axis in red; $5^{\prime}$ to $3^{\prime}$ orientation) represents a generic gene with the intron shown as a thinner region. The flanking regions are defined by the edge of the gene and the location of the GA microsatellites (purple triangles). Region 1 ( 250 nt; dark gray) is upstream of the 5' GA microsatellite. Region 2 ( $\sim 30$ nt; light gray) is between the GA microsatellite and the start codon. Region 3 ( $\sim 330 \mathrm{nt}$; light gray) is between the stop codon and the $3^{\prime}$ GA microsatellite. Region 4 ( 330 nt; dark dray) is downstream of the 3' GA microsatellite. The two colors in each line correspond to the two genes that were used in the pairwise comparison and match the gene colors shown in Figure 4. Three categories of pairwise diversity are i) high (squares) in regions flanking the gene, ii) low (circles) in all regions including the gene sequences, and iii) hybrid (triangles) where pairwise diversity is low in regions 1 and 2 and high in regions 3 and 4 . B. The microsatellites are boundaries for sequence conservation. Alignments of the genes and flanking sequences were used to calculate the entropy over a $30 \mathrm{nt}$ window that slides $1 \mathrm{nt}$ for each calculation. Entropy scores are shown for the analysis with all six genes (blue line) and for only the three D1 genes (red line). The black lines show the average diversity of the regions indicated on the $x$-axis for all six genes (dashed line), or only the three D1 genes (dotted line).

sequence diversity observed for the $S p 185 / 333$ genes may result, in part, from recent and frequent recombination [22]. The combination of gene and segmental duplications in addition to gene recombination may be a powerful system for generating and or maintaining sequence diversity in this gene family.

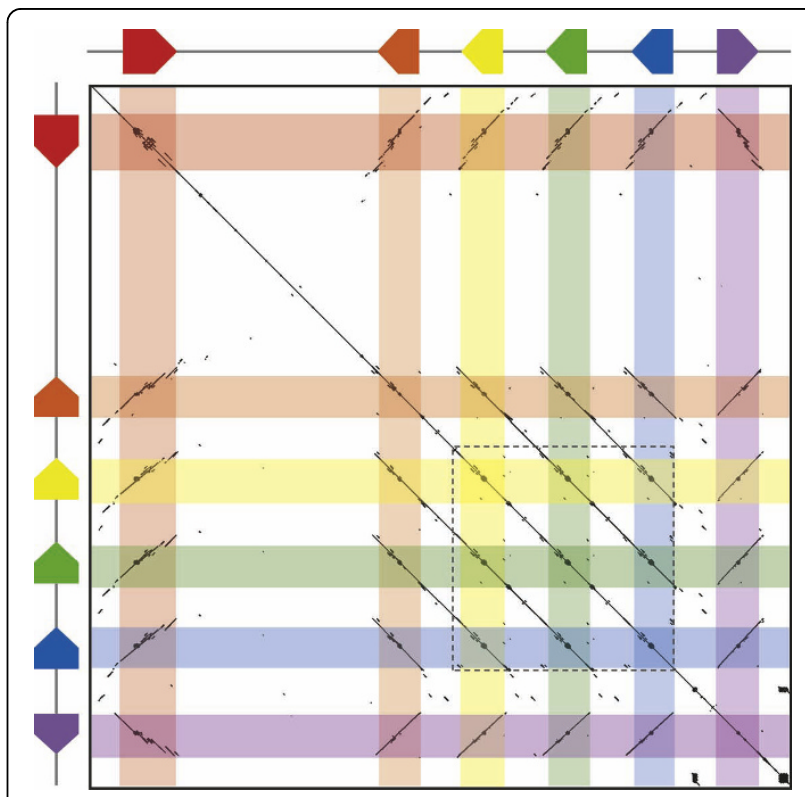

Figure 10 Dot plot of the Sp185/333 gene cluster shows gene and segment duplication. The Sp185/333 gene cluster of 34 kB is plotted against itself. The colored pentagrams indicate the positions of each of the Sp185/333 genes. Matching sequence appears as diagonal lines of dots indicating similar sequences are present in the same or opposite orientation. The genes plus a short region upstream of each of the genes are conserved. The dotted box illustrates the region of segmental duplications as indicated by the length and number of parallel, diagonal lines. The total length of the segmental duplications is $\sim 13.7 \mathrm{~kb}$ and consists of three segments that each include a D1 gene (yellow, green and blue).

\section{Heterogeneous gene clusters}

Many large gene families in organisms from plants to mammals have immune related functions. In humans, the major histocompatability complex (MHC) has over 160 genes that diversify through sequence exchange and duplication [59] and clusters of $R$ genes in higher plants also maintain diversity through sequence exchange and recombination (reviewed in [11]). The Sp185/333 gene family is another example of a large diverse immune related gene family (reviewed in [16]). The Sp185/333 cluster on the $7096 \mathrm{BAC}$ is positioned $6.1 \mathrm{~kb}$ from the end of the insert, which makes it unclear whether this cluster is one of several small isolated clusters in the genome, or whether it is the end of a large cluster with additional linked genes that might be identified from overlapping BACs. Examples of both large and small clusters of linked genes involved in immune responsiveness have been found in other organisms. The nucleotide binding, leucine-rich repeats (NB-LRR) subclass of $R$ genes in Arabidopsis has 149 members of which 109 are clustered into small groups consisting of two to eight genes $[60,61]$. Similarly, the sea urchin Toll-like 


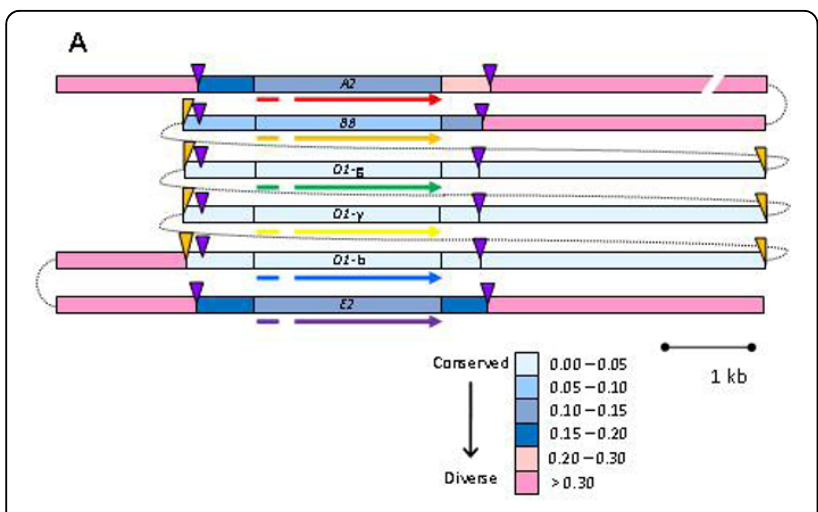

B

\begin{tabular}{|c|c|c|c|c|c|}
\hline & $\begin{array}{c}\text { Region } 1 \\
\text { distal }\end{array}$ & $\begin{array}{l}\text { Region } 2 \\
\text { proximal }\end{array}$ & Gene & $\begin{array}{l}\text { Region } 3 \\
\text { proximal }\end{array}$ & $\begin{array}{c}\text { Region } 4 \\
\text { distal }\end{array}$ \\
\hline $\begin{array}{l}A 2: 01-b \\
A 2: 01-g \\
A 2: D-y \\
\text { average }\end{array}$ & \begin{tabular}{|l|}
0.548 \\
0.565 \\
0.565 \\
0.559 \\
\end{tabular} & $\begin{array}{c}0.150 \\
0.153 \\
0.153 \\
0.152 \\
\end{array}$ & $\begin{array}{l}0.123 \\
0.123 \\
0.123 \\
0.123 \\
\end{array}$ & $\begin{array}{l}0.282 \\
0.282 \\
0.286 \\
0.283 \\
\end{array}$ & $\begin{array}{c}0.618 \\
0.625 \\
0.619 \\
\mathbf{0 . 6 2 1} \\
\end{array}$ \\
\hline $\begin{array}{l}88: 01-g \\
88: 01-b \\
88: 01-y \\
\text { average }\end{array}$ & \begin{tabular}{|c|}
0.040 \\
0.145 \\
0.040 \\
$\mathbf{0 . 0 7 5}$
\end{tabular} & \begin{tabular}{|l|}
0.075 \\
0.070 \\
0.073 \\
$\mathbf{0 . 0 7 3}$ \\
\end{tabular} & $\begin{array}{l}0.068 \\
0.067 \\
0.067 \\
\mathbf{0 . 0 6 7} \\
\end{array}$ & $\begin{array}{r}0.129 \\
0.129 \\
0.147 \\
0.135 \\
\end{array}$ & $\begin{array}{r}0.555 \\
0.544 \\
0.546 \\
\mathbf{0 . 5 4 8} \\
\end{array}$ \\
\hline $\begin{array}{l}01-b: 01-y \\
01-b: 01-g \\
01-g: 01-y \\
\text { average }\end{array}$ & \begin{tabular}{|l|}
0.169 \\
0.169 \\
0.000 \\
$\mathbf{0 . 1 1 3}$ \\
\end{tabular} & \begin{tabular}{|l|}
0.008 \\
0.013 \\
0.005 \\
0.009 \\
\end{tabular} & $\begin{array}{c}0.003 \\
0.003 \\
0.004 \\
\mathbf{0 . 0 0 3} \\
\end{array}$ & $\begin{array}{c}0.014 \\
0.000 \\
0.014 \\
0.009 \\
\end{array}$ & $\begin{array}{c}0.000 \\
0.013 \\
0.013 \\
\mathbf{0 . 0 0 9} \\
\end{array}$ \\
\hline $\begin{array}{l}E 2: 01-y \\
E 2: 01-g \\
E 2: 01-\mathrm{b} \\
\text { average }\end{array}$ & $\begin{array}{l}0.482 \\
0.482 \\
0.478 \\
\mathbf{0 . 4 8 1} \\
\end{array}$ & $\begin{array}{l}0.172 \\
0.172 \\
0.169 \\
0.171 \\
\end{array}$ & $\begin{array}{l}0.109 \\
0.109 \\
0.109 \\
\mathbf{0 . 1 0 9} \\
\end{array}$ & $\begin{array}{l}0.172 \\
0.182 \\
0.182 \\
0.179 \\
\end{array}$ & $\begin{array}{r}0.657 \\
0.650 \\
0.656 \\
0.654 \\
\end{array}$ \\
\hline
\end{tabular}

Figure 11 Duplications of genes and larger segments may be mediated by microsatellites. A. Alignment of the Sp185/333 genes and flanking regions. The genes (indicated as colored arrows) and proximal flanking regions between the GA microsatellites (purple triangles) are conserved. (For definitions of distal and proximal flanking regions, see the text and legend for Figure 9.) Conserved sequence between the GAT microsatellites (orange triangles) includes the three D1 genes and the associated intergenic regions. The GAT microsatellites are split into half triangles, except for the one located on the $5^{\prime}$ side of $D 1-b$, to show their positions relative to each gene. All of the intergenic sequence between the genes is shown, except for the region between $A 2$ and $B 8$. The fine dotted lines indicate how the sequences fit together on the BAC. The legend shows variations in color that relate to ranges of pairwise diversity scores based on results in B. B. Pairwise sequence diversity relative to the D1-y and D1-g genes. The level of sequence conservation is based on pairwise diversity scores for each of the Sp185/333 genes compared to the D1-y and D1-g genes. Colors in the table correlate to colors in the alignment in A.

receptor (TLR) genes are clustered in small groups that are spread throughout the genome [4,62]. Multiple large clusters of over 1,000 variant surface glycoprotein (VSG) genes in Trypanosoma brucei are distributed into 15 sizeable (40-60 kb) telomeric sites [63].

The six Sp185/333 genes on the 7096 BAC form a heterogeneous cluster with four different element patterns. Except for the $D 1$ genes, there is no correlation between proximity and sequence similarity among the linked genes on 7096 compared to genes that have been randomly isolated with unknown linkage (Figure 5). Although we suggest that the genes may be the result of duplications mediated by the GA microsatellites, it does not appear that the different element patterns of the clustered genes on 7096 are the result of tandem gene duplications from a single gene followed by sequence diversification. Consequently, the Sp185/333 gene cluster appears as a heterogeneous cluster of genes with different element patterns. Heterogeneous clusters of tandemly linked $R$ genes have been investigated in Arabidopsis in which more than ten clusters have intermingled genes from two different subfamilies: the Toll/ interleukin-1 LRR (TNL) subfamily and the coiled-coil region LRR (CNL) subfamily [60,61]. A proposed advantage of heterogeneous clusters is a block to gene homogenization and maintenance of diversity among the members of the cluster [64]. Two models have been proposed to explain the origins of heterogeneous clusters. The 'rapid rearrangement' model suggests that small areas consisting of one to a few genes are ectopically duplicated such that genes are copied to unlinked regions of the genome $[60,61]$. The 'conserved synteny' model suggests that large-scale segmental duplications are moved to new genomic locations, including different chromosomes $[11,65]$. Evidence for these models is based on the level of synteny, or lack thereof, in regions surrounding heterogeneous clusters. It is not clear whether either of these mechanisms functions within the Sp185/333 family, however, the notion of copying sequences from within the GA repeats to other locations of the genome with similar GA repeats is consistent with the heterogeneous mixture of Sp185/333 genes in the cluster. It is also consistent with a rapid rate of gene diversification as deduced from molecular clock analysis [16] and as proposed for rapid gene recombination [22].

\section{Gene conversion}

In addition to ectopic duplication of genes and segments to produce heterogeneous clusters, gene conversion may also be involved in sequence diversification, which may be promoted not only by the GA microsatellites, but also by the repeats and shared element sequences within the coding region. Six types of coding region repeats were first reported for ESTs and full length transcripts $[17,19]$ and are present in the second exon in both tandem and mixed interspersed organization (Figure 1) [15]. Within the repeats, shorter, simple repeats are also present [22]. In addition, many of the genes share element sequences and simple repeats, and, on a larger scale, the genes themselves can be viewed as imperfect repeats. If the similarity among the $S p 185 / 333$ sequences promotes crossovers and gene conversion, these activities would lead to sequence homogenization of the genes, the flanking regions, and possibly an entire region harboring Sp185/333 genes. This would be counter- 
productive for maintaining a diverse gene family with putative immunological functions. However, because sequence similarity among the genes decreases outside of the GA microsatellites, it suggests that regions that undergo sequence exchange are limited to the span between the GA microsatellites. The flanking microsatellites may act to block the progression of DNA strand exchange during crossovers and gene conversion, protecting the entire region from sequence homogenization including nearby Sp185/333 genes. An example of this type of result that has been experimentally observed in yeast [53]. Overall, we postulate two activities that may function simultaneously to generate and regulate sequence diversity among the cluster of $S p 185 / 333$ genes. Both the GA and GAT microsatellites may promote duplication of genes and larger segments leading to diversification perhaps by recombination. On the other hand, the shared sequences within the coding regions may promote an unknown level of gene conversion among both closely linked and unlinked genes that could preserve the heterogeneous nature of the cluster. Furthermore, strand exchange during gene conversion may be restricted to the genes and proximal flanking regions by the GA microsatellites that might block the spread of sequence homogenization to other genes within a tight cluster.

\section{Pseudogenes}

Gene fragments and pseudogenes are common in clusters of genes belonging to the same family $[66,67]$ and often result from common mechanisms of duplication and diversification such as unequal crossing over and tandem duplication. Surprisingly, no gene fragments have been found in the $S p 185 / 333$ family even after extensive searches of the genome, and only one pseudogene has been identified (of 171 genes sequenced) that appears to be the result of retrotransposition [15]. The remaining 170 sequenced genes have perfect open reading frames and splice signals. We speculate that the mechanisms that promote a rapid rate of gene diversification, as predicted by Buckley et al. [22] and as proposed above, may be under controls to avoid generating fragmented and non-functional genes. The flanking microsatellites and their putative block to DNA strand exchange may be involved in maintaining the reading frame fidelity while promoting diversification, given their location at the edges of the conserved flanking regions of the genes and at the edges of the tandem segmental duplications.

\section{A2 Gene Diversity}

The $A 2$ gene can be categorized as the outlier of the cluster for more than just reasons of distance. It has the highest sequence diversity compared to the other genes within the cluster (Table 4, Figure 11B) and it has variant GA microsatellites. Previous reports show that large genes such as $A 2$ (large genes always have elements 2 through 5, see Figure 1) are strikingly different from small genes ( $B, D$ and $E$ patterns, see Figure 1) that make up the rest of this cluster (see [15]). The sequences of the shared elements are entirely different [22] even though the large and small genes have a somewhat comparable complement of elements within the patterns (Figure 1). This prompted previous speculation that the $A 2$ genes may be spatially separated from the rest of the Sp185/333 genes, perhaps located in a separate cluster that would prevent recombination among large and small genes [22]. Consequently, it was unexpected to find an $A 2$ gene clustered near five Sp185/333 genes of the small category. Differences between the element diversity in the $A 2$ gene compared to the other genes in the cluster may be due to its separation from the other genes by $14 \mathrm{~kb}$, however, variations in the 3' flanking GA microsatellite may also be involved, preventing recombination between the $A 2$ gene and the other $S p 185 / 333$ genes within the cluster. If altered GA microsatellites are present in the other $A 2$ genes throughout the genome, this may restrict recombination or gene conversion to within the $A$ type element pattern category and maintain the sequence diversity for all of the $A$ type genes so that they share a similar element pattern and individual element sequences. A possible origin for the variation of the GA microsatellite associated with the $A 2$ gene is the LTR element fragments that are interspersed within this particular microsatellite. Whether this unique 3' GA microsatellite is common to all $A 2$ genes and to all genes in the large category and whether it is involved in maintaining separate element sequences between large vs. small genes is unknown and will require additional sequence data.

\section{Duplications imply deletions}

We hypothesize above that the recent segmental duplications that include the three $D 1$ genes within the cluster may be mediated by the GAT microsatellites. However, the presence of duplications implies that deletions also occur, which are difficult or impossible to detect. Preliminary PCR amplification of Sp185/333 sequences on two BACs, 7096 and 181662, indicated that both had Sp185/333 genes in different arrangements (data not shown). Initial sequencing of 181662 BAC (completed before 2006) resulted in 15 unordered contigs [116 kb, GenBank:AC181662.1] and included one contig with a complete second exon from a Sp185/ 333 gene with an open reading frame and a $3^{\prime}$ flanking GA microsatellite. In 2008, a finishing-level sequence for $181662(136.6 \mathrm{~kb})$ resulted in a single contig with no Sp185/333 genes, although GA microsatellites were present. Intergenic distances between GA microsatellites 
that flank the $S p 185 / 333$ genes on 7096 range from 1.9 to $2.5 \mathrm{~kb}$, although the spacing between $B 8$ and $A 2$ is much larger. The distances between large GA microsatellites (similar in repeat numbers to those surrounding the $S p 185 / 333$ genes reported here) on 181662 are 1.3, 1.4 and $2.6 \mathrm{~kb}$. This spacing is typical for the majority of the Sp185/333 genes as assayed by intergenic PCR amplification of genomic DNA [15]. We speculate that if the GA microsatellites mediate gene deletion and that this occurred during propagation of the BAC in culture, then the positions of the microsatellites on 181662 suggest that the Sp185/333 genes were spaced apart from each other similar to that for 7096. In comparison, results from another BAC, 076N15 (139 kb; see http:// www.spbase.org/SpBase/resources/bac_sequences.php for BAC sequence), that harbors homologues of two complement genes and does not have Sp1865/333 genes, has six large GA microsatellites that are spaced apart by $4-33.8 \mathrm{~kb}$. This spacing is much greater than reported here for either 7096 or 181662 . Although it is not known whether the deletion of Sp185/333 genes on 181662 was based on instability from the GA microsatellites, it is intriguing that these microsatellites may mediate gene both duplication and deletion.

\section{Gene copy number does not correlate with the level of gene expression}

Of the four different element patterns present in the genes within the cluster, two are of particular interest because of differences in both gene copy numbers and expression levels. The presence of three $D 1$ genes vs. single copies of genes with other element patterns is consistent with the previous observation that $D 1$ is the most commonly observed element pattern among genes [15]. Yet despite the higher frequency, expression of $D 1$ genes is relatively low compared to expression of $E 2$ genes $[18,19]$. Based on the cluster of genes reported here, reduced expression may be the result of a nonconsensus TATA box associated with the D1-g gene and non-consensus polyadenylation sites associated with the D1-g and D1-b genes. This raises the possibility that these genes may either be expressed less efficiently or they may be pseudogenes; however, it is not known whether other D1 genes in the genome also have variant TATA box and polyadenylation sites. On the other hand, the $E 2$ gene, which is most commonly expressed $[18,19]$, is observed less often in randomly sequenced genes [15] and is present as a single copy in the sequenced cluster. This suggests that increased expression of $E 2$ gene(s) in the genome may be the result of very active promoters that overcome an estimated lower gene copy number relative to $D 1$ genes (12-18 E2 genes vs. $30-45 D 1$ genes [68], KM Buckley, unpublished). It is important to note however, that although $E 2$ is the most commonly isolated element pattern among transcripts in response to immune challenge, a limited number of pathogen-associated molecular patterns (PAMPs) have been tested for the induction of Sp185/333 expression $[17,18,20]$. Testing additional PAMPs may show a variety of response levels for $S p 185 / 333$ genes with different element patterns that are present in the genome at different frequencies. Furthermore, the disparity in expression levels for genes with different element patterns may suggest that expression of each gene may be independently controlled by cis regulatory elements as opposed to a group expression control mechanism. This hypothesis is supported by comparisons between sequences from genes and messages for three sea urchins which shows that most of the messages (59\% to $93 \%$ for different individuals) are likely transcribed from a single gene per animal [68].

\section{Conclusions}

Conclusions: Diversification of the Sp185/333 gene family Previous studies of the Sp185/333 gene family and encoded proteins have provided evidence of several different mechanisms that ultimately diversify the pool of Sp185/333 proteins: gene recombination [22], RNA editing [68], and post-translational modifications $[21,69]$. To this body of data, we present a computational basis for postulating three additional diversification mechanisms; i) gene and segmental duplications driven by sequence similarities among the genes and the flanking microsatellites, ii) ectopic duplication, and iii) gene conversion promoted by coding region sequence similarities with strand exchange blocked by flanking microsatellites. Additional mechanisms for generating sequence diversity in the $S p 185 / 333$ gene family are undoubtedly possible. The Sp185/333 gene family in the purple sea urchin remains an interesting example of a complex invertebrate immune system that functions effectively in host protection against the myriad of possible pathogens in the marine environment.

\section{Abbreviations}

BAC: bacterial artificial chromosome; BCM-HGSC: Baylor College of Medicine - Human Genome Sequencing Center; CNL: coiled-coil region LRR; dNTP: deoxynucleotide triphosphate; DTCS: dye terminator cycle sequencing; FRePs: fibrinogen related proteins; gDNA: genomic DNA; LTR: long terminal repeat; MHC: major histocompatability complex; NB-LRR: nucleotide binding, leucine-rich repeats; PAMPs: pathogen-associated molecular patterns; PFG: pulsed-field gel; PFGE: pulsed-field gel electrophoresis; qPCR: quantitative polymerase chain reaction; SLS: sample loading solution; TBE: Tris borate EDTA; TLR: Toll-like receptor; TNL: Toll/interleukin-1 LRR; VCBPs: variable region-containing chitin-binding proteins; VSG: variant surface glycoprotein; WGS: whole genome shotgun.

\section{Acknowledgements}

The authors are indebted to Drs. Steven Salzberg and Michael Schatz for providing shotgun assembly expertise and to Drs. Erica Sodergren and George Weinstock for agreeing to re-sequence BAC 7096. Drs. Sham Nair 
and Liliana Florea provided helpful improvements to the manuscript. Trudy Gillevant assisted with BAC clone analysis. Katie Zaleski, Khin Sone and Caroline Rosa assisted with generating BAC subclones of Sp185/333 genes and intergenic regions. The research was funded by the National Science Foundation (MCB 07-44999) to LCS and a Weintraub research fellowship to KMB.

\section{Author details}

'Genomics and Bioinformatics Program, Department of Biochemistry, School of Medicine, The George Washington University, Washington DC, 20037, USA. ${ }^{2}$ Department of Biological Sciences, George Washington University, Washington, DC, 20052, USA. 'Department of Biology, Boston College, Boston, MA, USA. ${ }^{4}$ Department of Immunology, Sunnybrook Research Institute, University of Toronto, Toronto, ON, Canada. ${ }^{5}$ TECHLAB Inc, Blacksburg, VA, USA.

\section{Authors' contributions}

CAM and KMB carried out the computational and bench work. CAM wrote the first version of the mansucript. KMB edited the final version of the manuscript and revised the figures. RLE made subclones of the genes and intergenic regions from the BAC and directed the undergraduate students in the lab. LCS oversaw the research, generated the funding, and edited the manuscript and figures. All authors read and approved the final manuscript.

\section{Author Information}

Current positions:

CAM is a doctoral student in the Department of Biology, Boston College, Boston, MA. KMB is a postdoctoral researcher in the Department of Immunology, Sunnybrook Research Institute, University of Toronto, Toronto, ON, Canada. RLE is a research scientist at TECHLAB Inc. in Blacksburg, VA. LCS is a Professor of Biology at George Washington University, Washington DC.

Received: 7 June 2010 Accepted: 18 October 2010 Published: 18 October 2010

\section{References}

1. Raftos DA, Raison RL: Early vertebrates reveal diverse immune recognition strategies. Immunology and Cell Biology 2008, 86:479-481.

2. Flajnik MF, Du Pasquier L: Evolution of innate and adaptive immunity: can we draw a line? Trends in Immunology 2004, 25(12):640-644.

3. Loker ES, Adema CM, Zhang SM, Kepler TB: Invertebrate immune systemsnot homogeneous, not simple, not well understood. Immunological Review 2004, 198:10-24

4. Messier-Solek C, Buckley KM, Rast JP: Highly diversified innate receptor systems and new forms of animal immunity. Seminars in Immunology 2010, 22(1):39-47.

5. Zhang SM, Adema CM, Kepler TB, Loker ES: Diversification of Ig superfamily genes in an invertebrate. Science 2004, 305(5681):251-254

6. Schmucker D, Clemens JC, Shu H, Worby CA, Xiao J, Muda M, Dixon JE, Zipursky SL: Drosophila Dscam is an axon guidance receptor exhibiting extraordinary molecular diversity. Cell 2000, 101(6):671-684.

7. Schmucker D, Chen B: Dscam and DSCAM: complex genes in simple animals, complex animals yet simple genes. Genes and Development 2009, 23:147-156.

8. Brites D, McTaggart S, Morris K, Anderson J, Thomas K, Colson I, Fabbro T, Little TJ, Ebert D, Du Pasquier L: The Dscam homologue of the crustacean Daphnia is diversified by alternative splicing like in insects. Molecular Biology and Evolution 2008, 25(7):1429-1439.

9. Watson FL, Puttmann-Holgado R, Thomas F, Lamar DL, Hughes M, Kondo M, Rebel VI, Schmucker D: Extensive diversity of Ig-superfamily proteins in the immune system of insects. Science 2005, 309(5742):1874-1878.

10. Dong Y, Taylor HE, Dimopoulos G: AgDscam, a hypervariable immunoglobulin domain-containing receptor of the Anopheles gambiae innate immune system. PLoS Biology 2006, 4(7):e229.

11. McDowell JM, Simon SA: Molecular diversity at the plant-pathogen interface. Developmental and Comparative Immunology 2008, 32(7):736-744.

12. Cannon JP, Haire RN, Litman GW: Identification of diversified genes that contain immunoglobulin-like variable regions in a protochordate. Nature Immunology 2002, 3(12):1200-1207.
13. Cannon JP, Haire RN, Rast JP, Litman GW: The phylogenetic origins of the antigen-binding receptors and somatic diversification mechanisms. Immunolocal Reviews 2004, 200:12-22.

14. Dishaw L, Meuller MG, Gwatney N, Cannon JP, Haire RN, Litman RT, Amemiya CT, Ota T, Rowen L, Gluxman G, et al: Genomic complexity of the variable region-containing chitin-binding proteins in amphioxus. MBC Genetics 2008, 9:78.

15. Buckley KM, Smith LC: Extraordinary diversity among members of the large gene family, 185/333, from the purple sea urchin, Strongylocentrotus purpuratus. BMC Molecular Biology 2007, 8:68.

16. Ghosh JG, Buckley KM, Nair SV, Raftos DA, Miller C, Majeske AJ, Hibino T, Rast JP, Roth M, Smith LC: Sp185/333: A novel family of genes and proteins involved in the purple sea urchin immune response. Developmental and Comparative Immunology 2010, 34:235-245.

17. Nair SV, Del Valle H, Gross PS, Terwilliger DP, Smith LC: Macroarray analysis of coelomocyte gene expression in response to LPS in the sea urchin. Identification of unexpected immune diversity in an invertebrate. Physiological Genomics 2005, 22(1):33-47.

18. Terwilliger DP, Buckley KM, Brockton V, Ritter NJ, Smith LC: Distinctive expression patterns of $185 / 333$ genes in the purple sea urchin, Strongylocentrotus purpuratus: an unexpectedly diverse family of transcripts in response to LPS, beta-1,3-glucan, and dsRNA. BMC Molecular Biology 2007, 8:16.

19. Terwilliger DP, Buckley KM, Mehta D, Moorjani PG, Smith LC: Unexpected diversity displayed in CDNAs expressed by the immune cells of the purple sea urchin, Strongylocentrotus purpuratus. Physiological Genomics 2006, 26(2):134-144.

20. Rast JP, Pancer Z, Davidson EH: New approaches towards an understanding of deuterostome immunity. Current Topics in Microbiology and Immunology 2000, 248:3-16.

21. Dheilly NM, Nair SV, Smith LC, Raftos DA: Highly variable immuneresponse proteins (185/333) from the sea urchin Strongylocentrotus purpuratus: Proteomic analysis identifies diversity within and between individuals. Journal of Immunology 2009, 182:2203-2212.

22. Buckley KM, Munshaw S, Kepler TB, Smith LC: The $185 / 333$ gene family is a rapidly diversifying host-defense gene cluster in the purple sea urchin, Strongylocentrotus purpuratus. Journal of Molecular Biology 2008, 379:912-928.

23. Cameron RA, Samanta M, Yuan A, He D, Davidson E: SpBase: the sea urchin genome database and web site. Nucleic Acids Research 2009, , 37 Database: D750-D754.

24. Hoskins RA, Carlson JW, Kennedy C, Acevedo D, Evans-Holm M, Frise E, Wan KH, Park S, Mendez-Lago M, Rossi F, et al: Sequence finishing and mapping of Drosophila melanogaster heterochromatin. Science 2007, 316(5831):1625-1628.

25. Mendez-Lago M, Wild J, Whitehead SL, Tracey A, de Pablos B, Rogers J, Szybalski W, Villasante A: Novel sequencing strategy for repetitive DNA in a Drosophila BAC clone reveals that the centromeric region of the $Y$ chromosome evolved from a telomere. Nucleic Acids Research 2009, 37(7):2264-2273

26. Strathmann M, Hamilton BA, Mayeda CA, Simon Ml, Meyerowitz EM, Palazzolo MJ: Transposon-facilitated DNA sequencing. Proc Natl Acad Sci 1990, 88:1247-1250.

27. She X, Jiang Z, Clark RA, Liu G, Cheng Z, Tuzun E, Church DM, Sutton G, Halpern AL, Eichler EE: Shotgun sequence assembly and recent segmental duplications within the human genome. Nature 2004, 431(7011):927-930.

28. Medvedev P, Brudno M: Maximum likelihood genome assembly. Journal of Computational Biology 2009, 16(8):1101-1116.

29. Drost DR, Novaes E, Boaventura-Novaes C, Benedict Cl, Brown RS, Yin T, Tuskan GA, Kirst M: A microarray-based genotyping and genetic mapping approach for highly heterozygous outcrossing species enables localization of a large fraction of the unassembled Populus trichocarpa genome sequence. Plant Journal 2009, 58(6):1054-1067.

30. Cameron RA, Mahairas G, Rast JP, Martinez P, Biondi TR, Swartzell S, Wallace JC, Poustka AJ, Livingston BT, Wray GA, et al: A sea urchin genome project: sequence scan, virtual map, and additional resources. Proc Natl Acad Sci USA 2000, 97(17):9514-9518.

31. Multerer KA, Smith LC: Two CDNAs from the purple sea urchin, Strongylocentrotus purpuratus, encoding mosaic proteins with domains 
found in factor $\mathrm{H}$, factor $\mathrm{I}$, and complement components $\mathrm{C} 6$ and $\mathrm{C} 7$. Immunogenetics 2004, 56(2):89-106.

32. Sodergren $E$, Weinstock GM, Davidson EH, Cameron RA, Gibbs RA, Angerer RC, Angerer LM, Arnone MI, Burgess DR, Burke RD, et al: The genome of the sea urchin, Strongylocentrotus purpuratus. Science 2006, 314(5801):941-952.

33. Adams MD, Celniker SE, Holt RA, Evans CA, Gocayne JD, Amanatides PG, Scherer SE, Li PW, Hoskins RA, Galle RF, et al: The genome sequence of Drosophila melanogaster. Science 2000, 287(5461):2185-2195.

34. Schatz MC, Phillippy AM, Shneiderman B, Salzberg SL: Hawkeye: an interactive visual analytics tool for genome assemblies. Genome Biology 2007, 8(3):R34

35. Rebeiz M, Posakony JW: GenePalette: a universal software tool for genome sequence visualization and analysis. Developmental Biology 2004, 271(2):431-438.

36. Hall TA: BioEdit: a user friendly biological sequence alignment editor and analysis program for Windows 95/98/NT. Nucleic Acids Symposium Series: 1999 1999, 95-98.

37. Kumar S, Dudley J, Nei M, Tamura K: MEGA: A biologist-centric software for evolutionary analysis of DNA and protein sequences. Briefings in Bioinformatics 2008, 9:299-306.

38. Toth G, Deak G, Barta E, Kiss GB: PLOTREP: a web tool for defragmentation and visual analysis of dispersed genomic repeats. Nucleic Acids Res 2006, 34 Web Server: W708-W713.

39. Britten RJ, Cetta A, Davidson EH: The single-copy DNA sequence polymorphism of the sea urchin Strongylocentrotus purpuratus. Cell 1978, 15(4):1175-1186.

40. Green P: Phrap documentation. 1996 [http://www.phrap.org/phredphrap/ phrap.html].

41. Havlak P, Chen R, Durbin KJ, Egan A, Ren Y, Song XZ, Weinstock GM, Gibbs RA: The Atlas genome assembly system. Genome Research 2004, 14(4):721-732.

42. Lander ES, Linton LM, Birren B, Nusbaum C, Zody MC, Baldwin J, Devon K, Dewar K, Doyle M, FitzHugh W, et al: Initial sequencing and analysis of the human genome. Nature 2001, 409(6822):860-921.

43. Myers EW, Sutton GG, Delcher AL, Dew IM, Fasulo DP, Flanigan MJ, Kravitz SA, Mobarry CM, Reinert KH, Remington KA, et al: A whole-genome assembly of Drosophila. Science 2000, 287(5461):2196-2204.

44. Kapitonov W, Jurka J: Harbinger transposons and an ancient HARBI1 gene derived from a transposase. DNA Cell Biology 2004, 23(5):311-324

45. Li B, Xia Q, Lu C, Zhou Z, Xiang Z: Analysis on frequency and density of microsatellites in coding sequences of several eukaryotic genomes. Genomics Proteomics Bioinformatics 2004, 2(1):24-31.

46. Schlötterer $C$, Wiehe T: Microsatellites, a neutral marker to infer selective sweeps. Microsatellites: Evolution and Applications Oxford: Oxford University Press 1999, 238-247.

47. Schlotterer C: Evolutionary dynamics of microsatellite DNA. Chromosoma 2000, 109:365-371.

48. Bagshaw AT, Pitt JP, Gemmell NJ: High frequency of microsatellites in S. cerevisiae meiotic recombination hotspots. BMC Genomics 2008, 9:49.

49. Kong A, Gudbjartsson DF, Sainz J, Jonsdottir GM, Gudjonsson SA, Richardsson B, Sigurdardottir S, Barnard J, Hallbeck B, Masson G, et al: A high-resolution recombination map of the human genome. Nature Genetics 2002, 31(3):241-247.

50. Myers S, Bottolo L, Freeman C, McVean G, Donnelly P: A fine-scale map of recombination rates and hotspots across the human genome. Science 2005, 310(5746):321-324.

51. Jensen-Seaman Ml, Furey TS, Payseur BA, Lu Y, Roskin KM, Chen CF, Thomas MA, Haussler D, Jacob HJ: Comparative recombination rates in the rat, mouse, and human genomes. Genome Research 2004, 14(4):528-538.

52. Trifonov EN: Tuning function of tandemly repeating sequences: a molecular device for fast adaptation. In Evolutionary theory and processes: modern horizons, papers in honor of Eviatar Nevo. Edited by: Wassser SP. Amsterdam, The Netherlands: Kluwer Academic Publishers; 2003:1-24.

53. Gendrel C-G, Boulet A, Dutreix M: (CA/GT) microsatellites affect homologous recombination during yeast meiosis. Genes and Development 2000, 14:1261-1268.

54. Payen C, Koszul R, Dujon B, Fischer G: Segmental duplications arise from Pol32-dependent repair of broken forks through two alternative replication-based mechanisms. PLoS Genetics 2008, 4(9):e1000175.
55. Wahls WP, Wallace L, Moore PD: The Z-DNA motif $\mathrm{d}(\mathrm{TG}) 30$ promotes reception of information during gene conversion events while stimulating homologous recombination in human cells in culture. Molecular and Cellular Biology 1990, 10(2):785-793.

56. Napierala M, Dere R, Vetcher A, Wells RD: Structure-dependent recombination hot spot activity of GAA.TTC sequences from intron 1 of the Friedreich's ataxia gene. Journal of Biological Chemistry 2004, 279(8):6444-6454.

57. Murphy KE, Stringer JR: RecA independent recombination of poly[d(GT)-d (CA)] in pBR322. Nucleic Acids Research 1986, 14:7325-7340.

58. Bullock P, Miller J, Botchan M: Effects of poly[d(pGpT).d(pApC)] and poly[d $(p C p G) \cdot d(p C p G)]$ repeats on homologous recombination in somatic cells. Molecular and Cellular Biology 1986, 6(11):3948-3953.

59. Traherne JA: Human MHC architecture and evolution: implications for disease association studies. International Journal of Immunogenetics 2008, 35(3):179-192.

60. Meyers BC, Kozik A, Griego A, Kuang H, Michelmore RW: Genome-wide analysis of NBS-LRR-encoding genes in Arabidopsis. Plant Cell 2003, 15(4):809-834.

61. Richly E, Kurth J, Leister D: Mode of amplification and reorganization of resistance genes during recent Arabidopsis thaliana evolution. Molecular Biology and Evolution 2002, 19(1):76-94.

62. Hibino T, Loza-Coll M, Messier C, Majeske AJ, Cohen A, Terwilliger DP, Buckley KM, Brockton V, Nair S, Berney K, et al: The immune gene repertoire encoded in the purple sea urchin genome. Developmental Biology 2006, 300:349-365.

63. Boothroyd CE, Dreesen O, Leonova T, Ly Kl, Figueiredo LM, Cross GA, Papavasiliou FN: A yeast-endonuclease-generated DNA break induces antigenic switching in Trypanosoma brucei. Nature 2009, 459(7244):278-281

64. Leister D: Tandem and segmental gene duplication and recombination in the evolution of plant disease resistance gene. Trends in Genetics 2004, 20(3):116-122.

65. Li E: Chromatin modification and epigenetic reprogramming in mammalian development. Nature Reviews Genetics 2002, 3:662-673.

66. Rast JP, Messier-Solek C: Marine invertebrate genome sequences and our evolving understanding of animal immunity. Biological Bulletin 2008, 214:274-283.

67. Gilad Y, Man O, Paabo S, Lancet D: Human specific loss of olfactory receptor genes. Proc Natl Acad Sci USA 2003, 100(6):3324-3327.

68. Buckley KM, Terwilliger DP, Smith LC: Sequence variations between the $185 / 333$ genes and messages from the purple sea urchin suggest posttranscriptional modifications. Journal of Immunology 2008 181(12):2203-2212.

69. Brockton V, Henson JH, Raftos DA, Majeske AJ, Kim YO, Smith LC Localization and diversity of $185 / 333$ proteins from the purple sea urchin - unexpected protein-size range and protein expression in a new coelomocyte type. Journal of Cell Science 2008, 121(3):339-348.

\section{doi:10.1186/1471-2164-11-575}

Cite this article as: Miller et al: An Sp185/333 gene cluster from the purple sea urchin and putative microsatellite-mediated gene diversification. BMC Genomics 2010 11:575.

\section{Submit your next manuscript to BioMed Central and take full advantage of:}

- Convenient online submission

- Thorough peer review

- No space constraints or color figure charges

- Immediate publication on acceptance

- Inclusion in PubMed, CAS, Scopus and Google Scholar

- Research which is freely available for redistribution 